\title{
Metallothionein Isoforms as Double Agents - Their Roles in Carcinogenesis, Cancer Progression and Chemoresistance
}

\author{
MERLOS RODRIGO, M.; JIMENEZ JIMENEZ, A.; HADDAD, Y.; BODOOR, K.;
} ADAM, P.; KŘÍŽKOVÁ, S.; HEGER, Z; ADAM, V.

Drug Resistance Updates

2020, vol. 52, September 2020, pp. 1-13

ISSN: $1368-7646$

DOI: https://doi.org/10.1016/j.drup.2020.100691

Accepted manuscript

(C) 2020. This manuscript version is made available under the CC-BY-NC-ND 4.0 license (http://creativecommons.org/licenses/by-nc-nd/4.0/), doi: https://doi.org/10.1016/j.drup.2020.100691

Final version available from

https://www.sciencedirect.com/science/article/pii/S1368764620300182 
4 Miguel Angel Merlos Rodrigo ${ }^{1,2^{*}}$, Ana Maria Jimenez Jimemez ${ }^{1,2}$, Yazan Haddad $^{1,2}$, Khaldon

\section{Metallothionein Isoforms as Double Agents - Their Roles in}

\section{Carcinogenesis, Cancer Progression and Chemoresistance}

${ }^{1}$ Central European Institute of Technology, Brno University of Technology, Purkynova 123, CZ-612 00 Brno, Czech Republic

${ }^{2}$ Department of Chemistry and Biochemistry, Mendel University in Brno, Zemedelska 1, CZ61300 Brno, Czech Republic

${ }^{3}$ Department of Applied Biology, Jordan University of Science and Technology, 3030, Irbid, Jordan

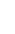
14 5

(6

\section{Corresponding Authors}

*Miguel Angel Merlos Rodrigo, Central European Institute of Technology, Brno University of Technology, Purkynova 123, CZ-612 00 Brno, Czech Republic; E-mail: miguel.merlos@ @eitec.vutbr.cz; phone: +420-5-4513-3350

†Vojtech Adam, Department of Chemistry and Biochemistry, Mendel University in Brno, Zemedelska 1, CZ-613 00 Brno, Czech Republic; E-mail: vojtech.adam@mendelu.cz; phone: $+420-5-4513-3350$ 


\section{Abstract}

2 Metallothioneins (MTs) are small cysteine-rich intracellular proteins with four major isoforms identified in mammals, designated MT-1 through MT-4. The best-known biological functions of MTs are their ability to bind and sequester metal ions and their active role in redox homeostasis. Despite these protective roles, numerous studies have demonstrated that changes in MT expression could be associated with the process of carcinogenesis and participation in cell differentiation, proliferation, migration, and angiogenesis. Hence, MTs have the role of double agents, i.e., working with and against cancer. In view of their rich biochemical properties, it is not surprising that MTs participate in the emergence of chemoresistance in tumor cells. Many studies have demonstrated that MT overexpression is involved in the acquisition of resistance to anticancer drugs, including cisplatin, anthracyclines, tyrosine kinase inhibitors and mitomycin. The evidence is slowly becoming available for a cellular switch in MT functions, showing that they indeed have two faces: protector and saboteur. Initially, MTs display anti-oncogenic and protective roles; however, once the oncogenetic process has started, MTs are utilized by cancer cells for progression, survival, and the coordination of chemoresistance. The duality of MTs can serve as a potential prognostic/diagnostic biomarker and can therefore open the door to new strategies in cancer treatment. Herein, we review and discuss MTs as tumor disease markers and describe their role in chemoresistance to distinct anticancer drugs.

Keywords: metallomics; tumor disease; drug resistance; cisplatin; anthracyclines, tyrosine kinase inhibitors 


\section{1. Introduction and main purpose of the review}

2 Metallothioneins (MTs) were discovered in 1957 by Margoshes and Vallee and identified as 3 low-molecular-mass sulfhydryl-rich proteins (Margoshes and Vallee, 1957). MTs have molecular masses of 6 to $7 \mathrm{kDa}$ and are characterized by an abundance of thiol groups (30\% cysteine) (Thirumoorthy et al., 2007). Interestingly, these major intracellular thiol-containing proteins are induced by numerous agents, including UV radiation, DNA damaging agents, or hormones and cytokines (Adam et al., 2016; Krizkova et al., 2012; Viarengo et al., 2000), whose levels are elevated upon oxidative stress (Eckschlager et al., 2009; Ruttkay-Nedecky et al., 2013).

In the last decade, it has been shown that MT overexpression is associated with chemoresistance and poor prognosis in a variety of malignancies, particularly prostate, breast, ovarian, head and neck cancer, non-small-cell lung cancer (NSCLC), melanoma, neuroblastoma and soft tissue sarcoma (Chen et al., 2015; Hayden et al., 2014; Krizkova et al., 2012; Lai et al., 2018; Lee et al., 2015; Raudenska et al., 2014; Si and Lang, 2018; Tariba et al., 2015; Weinlich et al., 2003; Wong and Stillman, 2018). The currently accepted mechanism of the role of MTs in chemoresistance is linked to their ability to chelate and neutralize drugs, thus shielding vital biomolecules from the high reactivity and cytotoxic effects of drugs and potentially leading to multidrug resistance (MDR) (Andrei et al., 2020; Bar-Zeev et al., 2017; Coppola et al., 2017; Gacche and Assaraf, 2018; Gonen and Assaraf, 2012; Li et al., 2016a; Livney and Assaraf, 2013; Taylor et al., 2015; Wijdeven et al., 2016; Zhitomirsky and Assaraf, 2016).

Therefore, it is not surprising that MT expression in tumor cells may be useful for personalizing the treatment strategy. However, it is difficult to distinguish whether increased MT expression is a factor inducing carcinogenesis and MDR or a factor inhibiting the induction and development of cancer because of the irreplaceable protective roles of these 
1 proteins in intracellular space. It should also be noted that increased MT expression has

2 protective cellular effects against carcinogenesis. On the other hand, the expression of MTs in

3 tumor cells protects them and increases the rate of tumor growth, resulting in decreased

4 patient survival (Masiulionyte et al., 2019; McGee et al., 2010). The anti-apoptotic functions

5 of MTs, (de)activation of transcription factors, and scavenging of reactive oxygen species

6 (ROS) are beneficial for cancer cell survival and proliferation and defense against the host

7 immune system, as depicted in Figure 1 (Dutsch-Wicherek et al., 2008; Krizkova et al.,

8 2009b; Pedersen et al., 2009; Thirumoorthy et al., 2007). Thus, MTs can be considered

9 "double agents" that play crucial roles in both physiological processes and cancer.

10 In the last decade, numerous reviews have revealed and highlighted the importance of MTs as

11 a cancer biomarker; however, only a few of them were focused on the specific role of MTs in

12 drug chemoresistance (Bizon et al., 2017; Pedersen et al., 2009), since some of the most

13 important critical reviews were published more than two decades ago (Doz et al., 1993; Ebadi

14 and Iversen, 1994; Kelley et al., 1988). We therefore address this topic by highlighting not

15 only the current state of the art but also future directions paving new pathways towards

16 precision medicine strategies. 


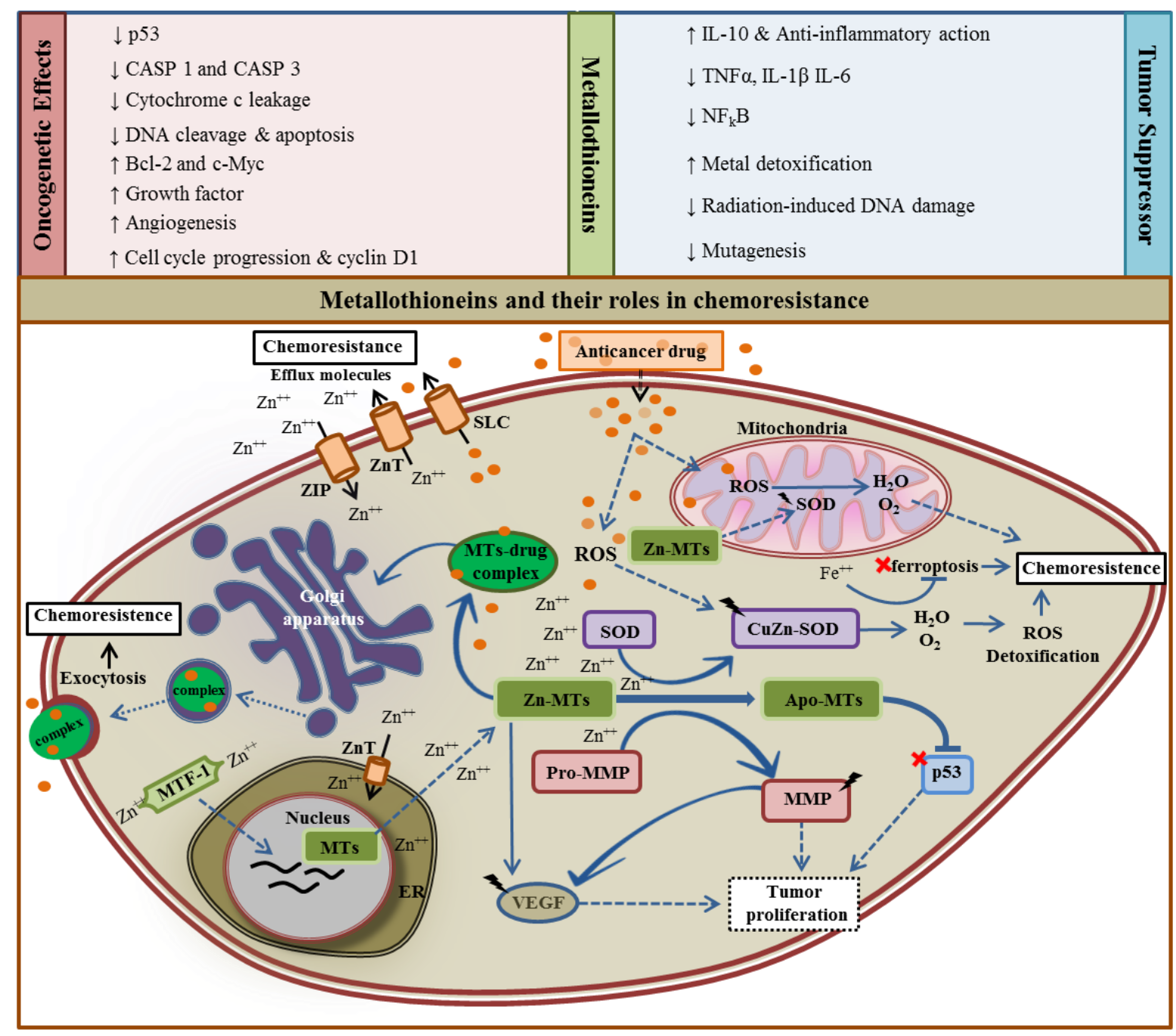

Figure 1. Involvement of MTs in various cancer-related processes: Oncogenesis (red), tumor suppressor (blue) and chemoresistance (brown) effects. MMP, matrix metalloproteinases; ER, endoplasmic reticulum; SOD, superoxide dismutase; $\mathrm{p} 53$, tumor protein $\mathrm{p} 53$; MTF-1, metal regulatory transcription factor; VEGF, vascular endothelial growth factor; ROS, reactive oxygen species; SLC, solute carrier group of membrane transport proteins; ZIP and ZnT, $\mathrm{Zn}^{++}$ transporter families.

\section{MT isoforms and structure}

Undoubtedly, it seemed incongruous to assume that a toxic metal would play a physiological

role in a mammal when a cadmium-binding protein was first identified in horse kidney more than half a century ago (Margoshes and Vallee, 1957). The mystery of MTs has undergone many developments and continues to stir interest in many fields of pathophysiology including oxidative stress, metal toxicity, bone development, liver and kidney functions, heart disease, 
1 diabetes, neurodegenerative disorders, cancer prognosis and, more recently, chemotherapy

2 development (Adam et al., 2016; Thirumoorthy et al., 2011).

Human MT isoforms are classified into four major groups: MT-1 and MT-2 are expressed in many tissues, particularly in the liver and kidneys; MT-3 is mostly expressed in neurons and male reproductive organs; and MT-4 is limited to the stratified squamous epithelium of the skin and upper gastrointestinal tract (Klaassen et al., 1999; Thirumoorthy et al., 2011). Gene expression profiling of MTs in human tissues revealed additional tissue-specific subgroups among the MT-1 and MT-2 isoforms. In addition to the broadly expressed isoforms (MT-2A, MT-1E, MT-1X, MT-1G, MT-1F and MT-1H), the following subtypes were clustered in expression profiles with MT-3 and MT-4: MT-1A (highly expressed in intestine and adipose tissue and moderately expressed in connective tissue, liver, lung eye and uterus), MT-1B (highly expressed in connective tissue and moderately expressed in blood), and MT-1M (moderately expressed in connective tissue, prostate, liver, lung intestine, uterus, stomach and brain) (Moleirinho et al., 2011).

Metal-loaded MTs display a unique 3D structure consisting of two domains separated by a short hinge region: the $\alpha$-domain spans the $C$-terminus with a large number of cysteines (11 residues binding four $\mathrm{Zn}$ ions), forming a more rigid globule, while the $\beta$-domain spans the $\mathrm{N}$ terminal half, including a rather flexible cluster of 9 cysteine residues that bind three metal ions (usually two $\mathrm{Cd}^{++}$and one $\mathrm{Zn}^{++}$) (Juarez-Rebollar et al., 2017; Klaassen et al., 1999). There is, however, some uncertainty as to the role of the protonation of the thiol groups themselves in MTs, as it is known that there are no disulfides. The protonation/deprotonation of these cysteines is believed to be dynamic, with approximately 3 protonated thiols in each domain that are constantly changing location (Szilagyi and Fenselau, 2000). Notably, MTs also have several long-chained lysine residues that face the solution but may also extend inward to neutralize free cysteines. The formation of intramolecular disulfides has been 
1 reported, with higher frequency in the $\alpha$-domain than the $\beta$-domain, and might play a 2 physiological role (Feng et al., 2006).

3 The above-described unique chemical properties determine the key roles of MTs in cellular

$4 \mathrm{Zn}^{++}$homeostasis by low-affinity binding of approximately 5-15\% of the cell's $\mathrm{Zn}$ ion pool in 5 combination with two classes of $\mathrm{Zn}$ transporter families, namely, Zrt- and Irt-like proteins 6 (ZIP, pumping $\mathrm{Zn}$ into cytoplasm) and $\mathrm{Zn}$ transporters (ZnT, pumping $\mathrm{Zn}$ away from

cytoplasm) (Golan et al., 2017; Kimura and Kambe, 2016). MT-3 was found to bind more $\mathrm{Cu}^{++}$than $\mathrm{Zn}^{++}$ions in brain tissue compared to MT-1 and MT-2 (Adam et al., 2016; Artells et al., 2014b). Another important and not yet well understood factor with a direct impact on the function is MT dimerization and oligomerization. Further study is required to shed light on these phenomena and their influence on MT binding affinity to metal ions and drugs (Krizkova et al., 2009a; Ryvolova et al., 2012; Szilagyi and Fenselau, 2000; Wilhelmsen et al., 2002). MT oligomerization can occur either in native/nonoxidative forms (Artells et al., 2014a) or in oxidative forms induced by high concentrations of $\mathrm{Cd}^{++}$, where MT subunits are covalently linked via disulfide bridges (Artells et al., 2014a; Zangger et al., 2001).

Interactions between MT isoforms and drugs can be either direct or indirect. An example of a direct interaction is the neutralization of otherwise effective metal ion-based drugs such as $\mathrm{Rh}_{2}(\mathrm{AcO})_{4}$ by MT-1A (Wong and Stillman, 2016) and cisplatin by MT-3 (Karotki and Vasak, 2009). In these cases, the metal ion replacement of $\mathrm{Zn}^{++}$begins in the $\beta$-domain. MTs can function as sensors and as transporters of metal ions through protein interactions. $\mathrm{Cd}^{++}$-loaded MT-1 and MT-2 isoforms bind directly to lipoprotein receptor-related proteins such as renal megalin (LPR-2) via their hinge region SCKKSCC motif (Klassen et al., 2004). Indeed, many interactions of metal-loaded MTs (and not apo-MTs) with specific proteins have been reported (Atrian and Capdevila, 2013). Briefly, the binding of MTs (mainly MT-3) to the transthyretin homotetramer enhances its ability to scavenge amyloid- $\beta$ and prevent the onset 
1 or progression of Alzheimer's disease (Adam et al., 2016). Similar claims have been reported

2 for $\alpha$-synuclein protein in Parkinson's disease, for prions in spongiform encephalopathies, and

3 for many secreted transport proteins (e.g., ferritin and albumin). In contrast, apo-MT-1

4 directly interacts with p53 to modulate $\mathrm{Zn}$ levels and p53 function. The p53 tumor suppressor

5 tetramer requires certain levels of $\mathrm{Zn}^{++}$for proper folding of its DNA-binding domain (Lehvy

6 et al., 2019). This modulation has been proven by the inactivation of p53 in the presence of

7 highly expressed MT-1 and in the presence of apo-MT-1. On the other hand, sorafenib

8 upregulates MT-1G via an NRF2 transcription factor-dependent mechanism and not through

9 p53 or HIF-1 $\alpha$ (Sun et al., 2016). The upregulation of MT-1G contributes to sorafenib

10 chemoresistance in hepatocellular carcinoma (HCC) by inhibiting a form of nonapoptotic

11 regulated cell death called ferroptosis (involving glutathione depletion, lipid peroxidation and

12 iron metabolism). The MT structural interactions and mechanisms involved in chemoresistance to various drugs are shown in Fig. 2 . 
A

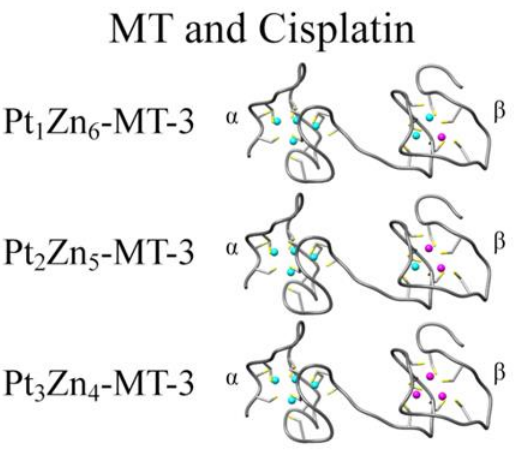

C
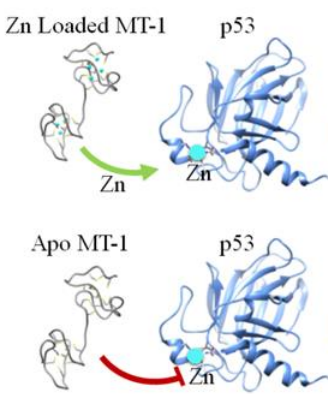

B

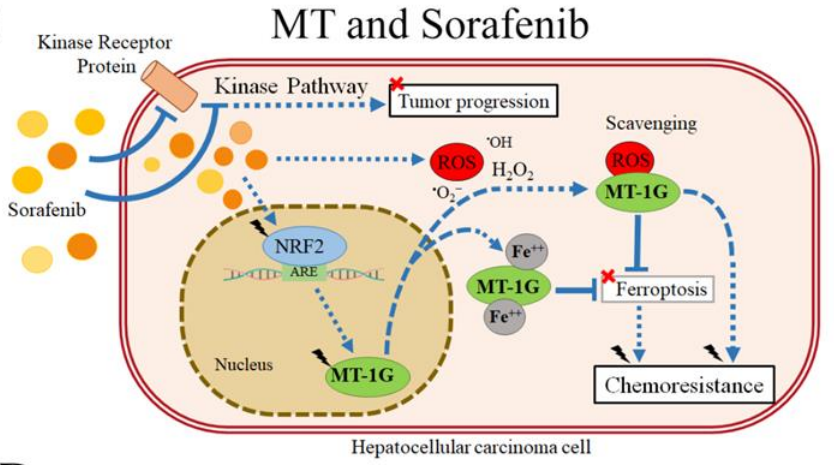

D

MT Dimers and Small Drugs
1

Figure 2. MT interactions and molecular mechanisms involved in drug chemoresistance. (A) The role of MT-3 in chemoresistance to cisplatin via replacement of $\mathrm{Zn}^{++}$(cyan) with $\mathrm{Pt}$ (magenta). (B) Chemoresistance to sorafenib via activation of NRF2 transcription factor regulating the expression of MT-1G, which prevents ferroptosis by scavenging ROS resulting from iron metabolism (Fenton reaction). (C) Apo-MT-1 removes $\mathrm{Zn}^{++}$(cyan) from $\mathrm{p} 53$ and forms an inactive complex, which prevents p53 from binding DNA and performing its function. (D) Inhibition of drugs by direct interaction with MTs. Reactive intermediates of doxorubicin (green) interact with mono- and dimer MT-1A via sulfhydryl oxidation. Crystal structures and homology models were used for these schematics (PDB ID: 3EXJ for p53 and 4MT-2 for MT). UCSF Chimera (University of California San Francisco, CA, USA) was used for visualization and rendering.

\section{MTs and cancer}

Taking into account the abovementioned information, MTs are double agents because they can also control the homeostasis of $\mathrm{Zn}^{++} / \mathrm{Cu}^{++}$in cells, which is essential for proliferation and differentiation (Adam et al., 2016; Krizkova et al., 2018). The antioxidant function of MTs protects the cells from free radicals and oxidative stress arising from mutagens, anticancer drugs, and radiation. The ability of MTs to bind $\mathrm{Cd}^{++}, \mathrm{Hg}^{++}, \mathrm{Pt}$ and other similar heavy metals protects cells from the toxicity of these metals (Krizkova et al., 2012; McNeill et al., 2019; Rahman et al., 2017; Wong and Stillman, 2018). On the other hand, it has been demonstrated that changes in MT expression could be associated with the process of carcinogenesis and 
1 cancer progression (Krizkova et al., 2018; Si and Lang, 2018). Herein, we summarize the current findings associating MTs and cancer.

\subsection{MT involvement in carcinogenesis}

Carcinogenesis is a process of tumor formation by the transformation of normal cells into cancer cells. This transformation originates from an abnormal "program" leading to a cascade of downstream changes (Jones and Baylin, 2007). All these changes at the cellular, genetic, and epigenetic levels disrupt the balance between proliferation and apoptosis (e.g., mutations and epimutations) and thus contribute to the development of cancer. MTs can promote tumor growth by regulating the supply of $\mathrm{Zn}^{++}$for proteins and the activity of $\mathrm{Zn}$-dependent transcription factors or by direct interaction with other proteins (Krizkova et al., 2018; Krizkova et al., 2012; Zalewska et al., 2014). MTs are also involved in the cell cycle regulation, cell proliferation, and the inhibition of apoptosis (Krizkova et al., 2009b; Si and Lang, 2018). It was previously observed that the cytoplasmic levels of MTs reached a maximum during the $\mathrm{G}_{1} / \mathrm{S}$ phase of the cell cycle (Nagel and Vallee, 1995) and that $\mathrm{Zn}^{++}$is required for the $\mathrm{G}_{1} / \mathrm{S}$ phase transition (He et al., 2019). Werynska et al. demonstrated the significance of MT-1/2 expression in the pathogenesis of lung adenocarcinoma. MT-1/2 expression was shown in proliferating NSCLC cells, pointing to the prognostic importance of the parallel expression of MT-1/2 and Ki-67, which are manifested mainly in the late $\mathrm{G}_{1}, \mathrm{~S}$, $\mathrm{G}_{2}$ and $\mathrm{M}$ phases of the cell cycle. Ki-67is one of the most frequently employed markers of cell proliferation (Werynska et al., 2011). Similar correlations were found in breast cancer (Gomulkiewicz et al., 2010; Jin et al., 2002), nasopharyngeal carcinoma (Jayasurya et al., 2000), colon adenocarcinoma (Dziegiel et al., 2003), basal cell carcinoma (Bieniek et al., 2012), and soft tissue sarcomas, such as malignant fibrous histiocytoma, liposarcoma, and synovial sarcoma (Dziegiel et al., 2005). MTs can transfer $\mathrm{Zn}^{++}$to transcription factors such as HIF-1 $\alpha$ and tumor suppressors such as p53 (Krizkova et al., 2012) and have been found to 
1 interact with NF- $\mathrm{BB}$ to mediate its anti-apoptotic effect (Krizkova et al., 2009b). MT overexpression is consistently associated with the presence of mutant p53 in breast cancer, anti-apoptotic effects, differentiation, proliferation, progression and poor prognosis (Sampaio et al., 2019). The interaction between MT-2A and Fas-associated protein with the death domain was connected with increased cell proliferation and apoptosis inhibition in colorectal cancer (CRC) via the NF- $\kappa$ B pathway (Marikar et al., 2016). Furthermore, MT expression can also protect cancer cells against a variety of pro-apoptotic stimuli, such as chemotherapeutics, heavy metals, oxidative stress, and radiation. For a detailed description, see the following sections.

Thus far, we do not know the underlying molecular mechanisms that explain why MT expression is increased in some cancers and downregulated in others. The alterations in the expression patterns of isoforms could be a possible explanation. Accordingly, the upregulation of specific MT isoforms was found to affect the growth of low-MT-expressing cancer cells. The transfection of MT-1F into CRC cells decreased their proliferation, colony formation and increased apoptosis (Yan et al., 2012). Low expression and tumor suppressor activity of MT-1H were found in prostate cancer cells (Zheng et al., 2017). The expression of MT-3 in PC-3 cells reduced cell growth (Dutta et al., 2002).

\section{2. $\quad$ MTs in tumor differentiation and angiogenesis}

Cellular differentiation is essential for tissue and organ development. Undifferentiated or poorly differentiated cells are more likely than differentiated cells to form tumors. Cancer is characterized by the grade of histological differentiation, which is used to determine cancer progression. Multiple studies have reported the participation of MTs in cell differentiation; however, these roles are also isoform-specific. The influence of extremely low-frequency electromagnetic fields on $\mathrm{Zn}^{++}$-MT-3 interaction during neuronal differentiation was studied. During this interaction, the expression of MT-3 was downregulated and the formation of 
$1 \mathrm{Zn}^{++}$-MT-3 complexes was increased to maintain $\mathrm{Zn}^{++}$homeostasis (Aikins et al., 2017). MTs were also found to negatively regulate IL-27-induced type 1 regulatory T-cell differentiation (Wu et al., 2013). MT-1G overexpression inhibited the all-trans retinoic acid-induced differentiation of NB-4 cells (Hirako et al., 2014). MT-2A overexpression enhanced the differentiation of osteosarcoma cells towards the osteogenic lineage (Habel et al., 2013). The expression of M-1F and MT-2A in histological grade 3 breast cancer was significantly increased compared to grades 1 and 2 (Jin et al., 2001; Jin et al., 2002). Similar results have also been published for ductal breast cancers, indicating connections to the chemoresistance, invasiveness, and clinical stage of breast cancers (Gallicchio et al., 2005; Gomulkiewicz et al., 2010; Rezk et al., 2015; Yap et al., 2009). The relationship between MT expression and tumor histological grade was also demonstrated in pancreatic ductal carcinoma (Ohshio et al., 1996), gallbladder carcinoma (Shukla et al., 1998), renal cancer (Mitropoulos et al., 2005), ovarian adenocarcinoma (Hengstler et al., 2001; McCluggage et al., 2002), and endometrial carcinoma (Bredholt et al., 2015). MT-1G was also found to be involved in the differentiation of CRC cells through the Notch signaling pathway and labile $\mathrm{Zn}^{++}$chelation and redistribution (Arriaga et al., 2017).

MTs can induce the upregulation of angiogenesis-related genes, such as matrix metalloproteinases (MMP-9 and $M M P-2)$ and $V E G F$, to form new blood vessels (Figure 3). This phenomenon is an important step in tumorigenesis to supply the tumor with oxygen and nutrients for its growth, progression and metastasis. MMPs are associated with tumor progression because of their role in remodeling of the extracellular matrix, angiogenesis and revascularization (Cho et al., 2019). For instance, MMP-9 (i.e., gelatinase B) was found to interact directly with MTs (Zalewska et al., 2014). Following MT knockout, dysfunction of endothelial cells (ECs), smooth muscle cells and macrophages was observed in mice. MMP-9, 
1 PDGF, and VEGF were significantly downregulated in these mice, which contributed to these

2 dysfunctions (Zbinden et al., 2010).

3 MT-1 was found to be expressed in vascular endothelial cells at the site of angiogenesis, and

4 its downregulation resulted in inhibited cell proliferation, migration and angiogenesis in vivo

5 (Miyashita and Sato, 2005). Decreased levels of the growth factors $\beta$-FGF, TGF- $\beta 1$, and

6 VEGF mediated decreased angiogenesis and regeneration in MT-1/2-deficient mice after

7 cortical freeze injury. These mice also displayed a dramatic reduction in IL-6-induced

8 angiogenesis (Miyashita and Sato, 2005; Penkowa et al., 2000). The expression of VEGF was

9 slightly increased in breast cancer cell lines after exposure to $\mathrm{Zn}^{++}$ions, which also led to 10 increased expression of selected MT isoforms. These results suggested a correlation between

11 MTs and VEGF expression in these cell lines (Wierzowiecka et al., 2016). In brain ECs, MT-

123 was found to induce the expression of VEGF through an HIF-1 $\alpha$-dependent mechanism

13 (Kim et al., 2008). MT-2 was also found to induce the expression of VEGF in the regulation

14 of EC proliferation, migration and angiogenesis (Schuermann et al., 2015). 


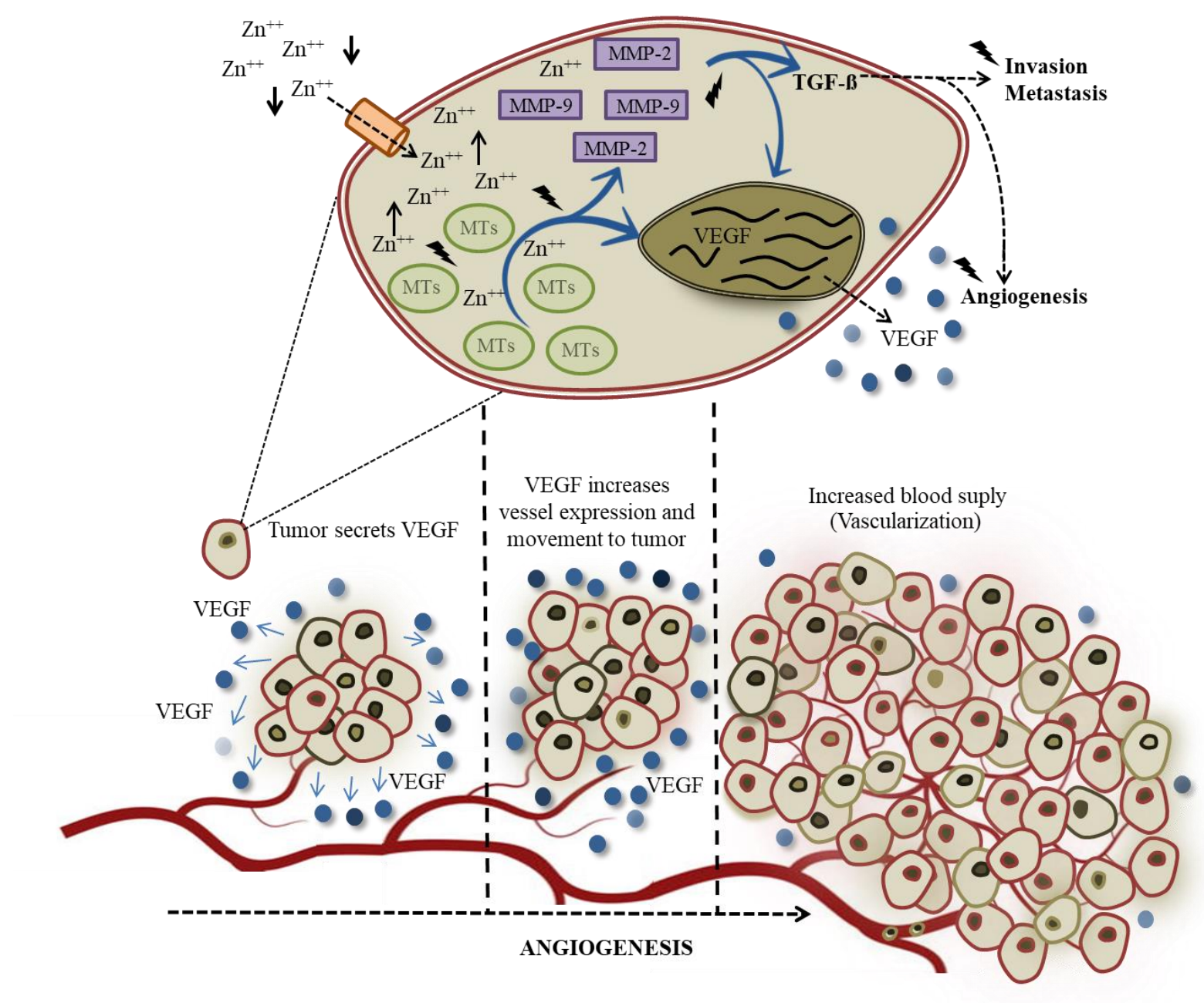

2 Figure 3. Roles of MTs in tumor angiogenesis. $\mathrm{Zn}^{++}$compartmentalization within the tumor 3 favors invasion, metastasis, and angiogenesis mediated by MTs and matrix metalloproteinases 4 (MMP-2 and MMP-9). MTs and MMPs act upstream of VEGF and TGF- $\beta$ in regulating 5 angiogenesis. In turn, these new blood vessels supply the growing tumors with oxygen and 6 nutrients, allowing the cancer cells to invade nearby tissue, thereby spreading throughout the 7 bloodstream and culminating in metastasis.

\subsection{The role of MTs in tumor metastasis}

During cancer development, the stage of tumor metastasis is reached when cells from the

primary tumor undergo dissemination to a secondary site. Some studies have shown that MTs collaborate with invasion, spread, and metastasis in various types of cancers, so they can be used as markers in aggressive cancers (Pedersen et al., 2009; Si and Lang, 2018). MTs may have a significant role in oncogenesis, but their expression is divergent in different kinds of 
1 human tumors, and it is related to tumorigenesis and tumor progression ( $\mathrm{Si}$ and Lang, 2018).

2 Moreover, MT isoforms were also identified in numerous benign lesions with different expression patterns in these tissues (Fic et al., 2013; Krizkova et al., 2012; Pula et al., 2015). As mentioned earlier, a few studies reported that MT expression was downregulated in some cancers (e.g., gastric, HCC and CRC), while in other cancers, it was upregulated (breast, kidney, lung and prostate). Hence, MT expression is associated with the type and status of the tumors and might be a useful tool for the choice of therapy or for cancer diagnosis (Kim et al., 2011). For example, MT overexpression (MT-1/2) was correlated with tumor-infiltrating macrophages (a known predictive value of progression and correlated with metastasis formation) in cutaneous malignant melanoma, as previously reported by Emri et al. (Emri et al., 2013). Furthermore, Suzuki et al. suggested that these two MTs have protective values in the initial stages of skin carcinogenesis (Suzuki et al., 2003), accelerating wound healing in keratinocytes (Morellini et al., 2010), but once carcinogenesis occurs, MTs promote tumor growth (McGee et al., 2010).

MT-1 and MT-2 operate as protective agents against Helicobacter pylori infection (which over time may result in the development of gastric cancer) (Tran et al., 2007). However, MT2 has also been identified as a potent tumor suppressor that prevents the development of gastric cancer (Pan et al., 2013a; Pan et al., 2016; Pan et al., 2013b). Decreased expression of MT-2 and MT-3 was shown in gastric cancer specimens compared to healthy gastric mucosa (Deng et al., 2003; Ebert et al., 2000). Additionally, MT overexpression was correlated with lymph node metastasis in gastric cancers (Galizia et al., 2006). Other studies showed low expression of MT-1E, MT-1F, MT-1G, MT-1H, MT-1M, MT-1X, and MT-2A isoforms in the CRC mucosa compared with normal mucosa, suggesting that these MT isoforms are potent tumor suppressors (Fic et al., 2013; Janssen et al., 2000; Pedersen et al., 2009; Yan et al., 2012). In HCC samples, some molecular studies confirm the specific downregulation of 
1 MT isoforms, including $M T-1 A, M T-1 E, M T-1 G, M T-1 M, M T-1 H, M T-1 X$, and $M T-2$, with no

2 differences in regard to $M T-1 B, M T-1 E$, or $M T-1 X$ (Datta et al., 2007; Mao et al., 2012). In addition, the analysis of patients' clinical and pathological data revealed that MT expression was inversely correlated with the malignancy grade of the tumors and the clinical advancement stage of cancer (Endo et al., 2003; Endo et al., 2004; Tao et al., 2007). MT-1G downregulation has also been observed in hepatoblastoma (Sakamoto et al., 2010). Furthermore, the transcript levels of $M T-2$ were significantly upregulated in renal cancer, whereas $M T-1 A$ and $M T-1 G$ were downregulated (Nguyen et al., 2000). The MT-3 gene was among the reported downregulated metastasis genes involved in primary solid tumors in this type of cancer (Fu et al., 2013).

In a study of HCC cells, Lui et al. demonstrated that $M T-1 X$ overexpression delayed the cell cycle and promoted apoptosis in vitro and in vivo. Moreover, MT-1X suppressed tumor growth and promoted lung metastasis. The study also demonstrated that $M T-1 X$ caused the inactivation of NF- $\kappa \mathrm{B}$ signaling, thus resulting in cell cycle arrest and apoptosis (Liu et al., 2018).

MT expression in normal lung tissue seems to protect against dangerous factors that can induce oncogenesis (Inoue et al., 2008; Takaishi et al., 2010). However, lung epithelial cells with a high level of MTs may contribute to the later induction of oncogenesis (Person et al., 2013). Thus, it seems that MTs protect lung cells from damaging factors until some critical event; however, once carcinogenesis begins, they contribute to tumor progression (McGee et al., 2010; Werynska et al., 2011).

MTs are also involved in the oncogenesis of head and neck carcinomas. Hishikawa et al. showed that MT expression in squamous cell carcinoma of the head and neck was positively correlated with metastasis and tumor cell proliferation in the esophagus (Hishikawa et al., 1997). Brazao-Silva et al. demonstrated a different behavior of MTs in normal oral mucosa 
1 and oral squamous cell carcinoma. Both tissues displayed the same expression of $M T-1 B$ and

$M T-1 H$. On the other hand, oral squamous cell carcinoma exhibited downregulation of $M T$ $1 A, M T-1 X, M T-3$ and $M T-4$, in contrast to upregulation of $M T-1 F$ expression. Moreover, the patients with the worst prognosis exhibited downregulation of $M T-1 G$, while $M T-1 X$ overexpression was observed in nonmetastatic cases, in contrast to $M T-3$ overexpression, which was observed solely in the patients who presented with metastasis (Brazao-Silva et al., 2015). Increased expression of MT-1 and MT-2 in cervical cancer cells has been demonstrated previously. MT-1/2 expression is prominent in the basal layer cells of the normal uterus, in cervical intraepithelial neoplasia, and during tumor progression to stage IIIII (Theocharis et al., 2004). Endometrial carcinomas also display an increase in MT-1/2 that is positively correlated with higher tumor grade, higher tumor cell proliferative capacity, and reduced patient survival (Dutsch-Wicherek et al., 2008; Theocharis et al., 2004). Furthermore, $\mathrm{Fu}$ et al. demonstrated a significant positive association of $M T-1 G$ hypermethylation with lymph node metastasis in 178 papillary thyroid cancer patients (Fu et al., 2013).

Several studies have also concluded that the expression of distinct MT isoforms was associated with poor survival, tumor grade, and recurrence rate in highly malignant invasive ductal breast carcinomas (Bay et al., 2006; Cherian et al., 2003; Dziegiel et al., 2004; Gallicchio et al., 2005; Surowiak et al., 2006). All isoforms of MT-1, MT-2 and MT-3 have been detected in breast cancer tissue samples (Jin et al., 2002; Jin et al., 2004; Sens et al., 2002). Moreover, different expression patterns of $M T-1$ have been noted in cases of breast cancer with confirmed lymph node metastases (Dutsch-Wicherek et al., 2005). MT-1F has been positively correlated with malignancy grade (Jin et al., 2001), whereas $M T-1 E$ expression has been found in estrogen receptor-negative breast cancer cell lines (Friedline et al., 1998; Jin et al., 2001). In addition, $M T-2 A$ has been identified as the most abundant in breast cancer and plays a protective role in these cancer cells, with high expression involved 
1 in cell cycle regulatory capabilities (Lai et al., 2010; Lai et al., 2011). MT overexpression can

2 also induce other proteins, e.g., MT-2A induces the overexpression of MMP-9 with

3 subsequent induction of the invasive phenotype of breast cancer cells (Emri et al., 2013). In

4 numerous cases of breast cancer, the expression status of estrogen and progesterone receptors

5 was inversely correlated with MT-1 and MT-2 expression (El Sharkarvy and Farrag, 2008;

6 Gomulkiewicz et al., 2010).

7 In normal prostate tissue, differential MT expression was observed, namely, high expression

8 in low-grade cancers and lack of expression in high-grade cancers (Wei et al., 2008).

9 Gumulec et al. found differential expression of MTs in prostate cancer at the RNA and protein levels, particularly an increase in MT-1A-encoding mRNA levels and a simultaneous decrease in the MT-1/2 proteins (Gumulec et al., 2012). In addition, Han et al. demonstrated that low expression of $M T-1 H$ attenuated cell migration and cell growth (Han et al., 2013). On the other hand, $M T-1 G$ hypermethylation has been linked to the aggressiveness of lesions and is characteristic of high-grade prostate cancers (Henrique et al., 2005). In summary, MTs are involved in tumor growth, differentiation, and metastasis. The up- and downregulation of MTs contributes to metastasis and increases the adhesion, invasion, and migration of tumor cells. This variation in expression behavior depends on the MT isoforms and the tumor type, as well as on the tumor microenvironment (Theocharis et al., 2004).

\subsection{MTs as cancer biomarkers}

MTs manifest varying expression levels in carcinomas and thus may serve as valuable cancer biomarkers in certain malignances. An interesting meta-analysis study was conducted to determine the characteristics of MT expression in benign and malignant tumors originating from different tissues. The results of immunohistochemical evaluation of MTs in benign tumors revealed an important downregulation, in contrast to malignant tumors, particularly since this difference appeared in many tumors (Zhang et al., 2014). In addition, Gumulec et 
1 al. evaluated the associations between MT expression and clinicopathological characteristics, tumor type, stage, grade, prognosis, and survival using a meta-analysis. While no associations were identified between MTs and tumor staging, a positive association was found with tumor grade. In particular, strong associations were observed in breast, ovarian, uterine and prostate cancers (Gumulec et al., 2014b). There are currently a number of good systematic reviews of MTs as biomarkers for cancer diagnosis (Babula et al., 2012; Bizon et al., 2017; Cherian et al., 2003; Dziegiel et al., 2016; Felizola et al., 2014; Gumulec et al., 2012; Jin et al., 2004; Krizkova et al., 2009b; Krizkova et al., 2012; Malavolta et al., 2016; Miles et al., 2000; Si and Lang, 2018; Takahashi, 2012). Associations of MTs with several diseases, such as Alzheimer's disease (Adam et al., 2016; Roy et al., 2017; Waller et al., 2018), circulatory diseases (Billaud et al., 2018; Cong et al., 2016; Yu et al., 2018) and amyotrophic lateral sclerosis (Ono, 2017), have also been found. Furthermore, strong evidence exists regarding the potential role of MTs in the immune system and inflammatory processes (Pankhurst et al., 2011; Waeytens et al., 2009; Youn et al., 2002).

\section{MTs in chemoresistance to anticancer drugs}

Chemoresistance, a complex system of heterogeneous biochemical mechanisms, is mainly embodied in the insensitivity of cancer cells to therapy and is considered a key factor in the failure of anticancer chemotherapy (Andrei et al., 2020; Bar-Zeev et al., 2017; Coppola et al., 2017; Gacche and Assaraf, 2018; Gonen and Assaraf, 2012; Hanahan and Weinberg, 2011; Kopecka et al., 2020; Li et al., 2016a; Livney and Assaraf, 2013; Taylor et al., 2015; Wijdeven et al., 2016; Zhitomirsky and Assaraf, 2016). In view of the rich biochemical properties of MTs, it is not surprising that they are believed to participate in the emergence of chemo- and/or radioresistance in tumor cells. It has been suggested that MTs provide protection against apoptosis and promote cell proliferation, leading to tumorigenesis (Krzeslak et al., 2014). Drug resistance has been postulated to be mainly the result of 
1 protection against ROS and anti-apoptotic factors and of the direct sequestration of alkylating agents by MT cysteines (Habel et al., 2013; Lai et al., 2011). Recent evidence also supports interactions with other important thiol compounds, indicating the involvement of glutathiones in chemoresistance (Kim et al., 2019; Russi et al., 2019; Tanner et al., 2002); however, a direct mechanism of interaction has not yet been elucidated. Table 1 shows an overview of the upregulated expression of MTs in chemoresistance to anticancer drugs. As shown by Yap et al., siRNA-based silencing of MT-2A in MCF-7 cells exposed to doxorubicin (Dox) led to a significant reduction in cell viability and a corresponding increase in apoptosis (Yap et al., 2009). Similarly, poor survival was observed in bladder tumors expressing higher levels of MTs due to their mediation of resistance against alkylating agents (Wulfing et al., 2007). MTs were also shown to initiate Dox resistance in NSCLC (Mattern and Volm, 1992), in which a significant relationship between MT expression and resistance was found. Moreover, a significant correlation was also documented between MT and glutathione $S$-transferase P enzyme expression. However, the role of MTs in the development of chemoresistance in clinical conditions is still controversial, and their importance may vary in different tumors.

Table 1. Overview of the upregulated expression of MTs in chemoresistance to anticancer drugs.

\begin{tabular}{|c|c|c|c|}
\hline Cancer type & MT isoforms & Chemotherapy & References \\
\hline Testicular cancer & Total MTs & cisplatin & $\begin{array}{c}\text { (Chin et al., 1993; Tariba et } \\
\text { al., 2015) }\end{array}$ \\
\hline Esophageal cancer & Total MTs & cisplatin & $\begin{array}{c}\text { (Hishikawa et al., 1997; Hou } \\
\text { et al., 2017) }\end{array}$ \\
\hline Urothelial carcinoma & MT-1A, MT-1B & cisplatin & (Skowron et al., 2018) \\
\hline Neuroblastoma & MT-3 & cisplatin & (Rodrigo et al., 2018) \\
\hline \multirow{2}{*}{ Bladder cancer } & MT-2A & mitomycin, cisplatin & $\begin{array}{c}\text { (Lynn et al., 2003; Singh et } \\
\text { al., 1995) }\end{array}$ \\
\cline { 2 - 4 } & Total MTs & cisplatin & $\begin{array}{c}\text { (Hayden et al., 2014; Kondo } \\
\text { et al., 1992; Wulfing et al., } \\
\text { 2007) }\end{array}$ \\
\hline \multirow{2}{*}{ Prostate cancer } & MT-2A, MT-1E, MT-1G, MT- & cisplatin & $\begin{array}{c}\text { (Dutta et al., 2002; Gumulec } \\
\text { et al., 2014a; Henrique et al., } \\
\text { 2005; Smith et al., 2006) }\end{array}$ \\
\cline { 2 - 4 } & 1R, MT-1 L, MT-3, Total MTs & mitoxantrone & (Dutta et al., 2002) \\
\cline { 2 - 4 } & MT-1E, MT3 & cadmium, arsenic & $\begin{array}{c}\text { (Dutta et al., 2002; Lee et al., } \\
\text { 1999) }\end{array}$ \\
\cline { 2 - 4 } & MT-1, MT-2, MT1-E, MT-3 & &
\end{tabular}




\begin{tabular}{|c|c|c|c|}
\hline & MT-1E, MT3 & etoposide & (Dutta et al., 2002) \\
\hline & MT-1E, MT3 & vinblastine & (Dutta et al., 2002) \\
\hline & MT-1E, MT3 & paclitaxel & (Dutta et al., 2002) \\
\hline & MT1-X & genistein & (Raschke et al., 2006) \\
\hline \multirow{3}{*}{ Gastric cancer } & MT-1G & docetaxel & (Pan et al., 2016) \\
\hline & MT-1X & irinotecan & (Chun et al., 2004a) \\
\hline & MT-1G & cisplatin & (Suganuma et al., 2003) \\
\hline NSCLC & MT-1H & doxorubicin & (Mattern and Volm, 1992) \\
\hline Ovarian cancer & Total MTs, MT-2A & cisplatin & $\begin{array}{l}\text { (Andrews et al., 1987; } \\
\text { Cheng et al., 2006; Surowiak } \\
\text { et al., 2005) }\end{array}$ \\
\hline CRC & MT-1G & oxaliplatin & $\begin{array}{c}\text { (Arriaga et al., 2017; Arriaga } \\
\text { et al., 2014) }\end{array}$ \\
\hline Breast cancer & MT-1/2 & doxorubicin & (Kepinska et al., 2018) \\
\hline \multirow{2}{*}{$\mathrm{HCC}$} & $\begin{array}{c}\text { MT-1G, MT-1B, MT-1E, MT- } \\
\text { 1L, MT-1M }\end{array}$ & sorafenib & $\begin{array}{l}\text { (Houessinon et al., 2016; } \\
\text { Reeves, 2016; Sun et al., } \\
\text { 2016) }\end{array}$ \\
\hline & Total MTs & carboplatin & $\begin{array}{c}\text { (Choi et al., 2004; Endo et } \\
\text { al., 2004) }\end{array}$ \\
\hline Lymphoma & MT-2A & gallium nitrate & $\begin{array}{c}\text { (Yang and Chitambar, 2008; } \\
\text { Yang et al., 2007) }\end{array}$ \\
\hline Gastrointestinal Stromal Tumor & Total MTs & imatinib & (Perez-Gutierrez et al., 2007) \\
\hline Cardioprotection* & Total MTs & doxorubicin & $\begin{array}{l}\text { (Guo et al., 2014; Jing et al., } \\
\text { 2011; Sun et al., 2001; Wang } \\
\text { and Kang, 1999) }\end{array}$ \\
\hline
\end{tabular}

*Not a cancer type but another biological functionality described for MTs.

\subsection{MTs and chemoresistance to platinum-based drugs}

To understand pretarget resistance in metallo-chemotherapeutics, it is necessary to investigate the mechanisms responsible for metal-protein binding reactions. Platinum drugs, including cisplatin, carboplatin, and oxaliplatin, are well-known chemotherapeutic drugs. They have been utilized for the treatment of numerous human cancers, including brain, head and neck, lung, breast, neuroblastoma, ovarian, bladder, and testicular cancers, for decades (Chin et al., 1993; Esteban-Fernandez et al., 2008; Ravera et al., 2019; Wang et al., 2019). They are also effective against various types of cancers, including carcinomas, germ cell tumors, lymphomas, and sarcomas. Their mode of action has been linked to their ability to crosslink the $\mathrm{N}_{7}$ reactive center of purine residues and thereby cause DNA damage in cancer cells, blocking cell division and subsequently inducing apoptosis (Dasari and Tchounwou, 2014). The intracellular level of MTs may play an important role in regulating cellular responsiveness to DNA-targeted antineoplastic agents (Basu, 2018). The antitumor activity of 
1 cisplatin is believed to be due to its interaction with chromosomal DNA (Florea and

2 Büsselberg, 2011; Rebillard et al., 2008; Rocha et al., 2018). It is still uncertain which MT isoforms are increased in cells with acquired resistance to platinum drugs. However, we show

in this review that MT levels correlate with the sensitivity of human tumors and cell lines to platinum drugs. Cisplatin resistance remains a major impediment to the effective treatment of many types of cancers. The cellular inactivation of cisplatin and subsequent sequestration can be mediated by MTs that chelate platinum and prevent interaction with tumor cell DNA (Hou et al., 2017; Maleckaite et al., 2019; Skowron et al., 2018; Wong and Stillman, 2018). In 1997, Hishikawa et al. suggested that MT expression in squamous cell carcinoma of the esophagus is a major determinant of cisplatin resistance and may be a predictor of poor prognosis (Hishikawa et al., 1997). To date, MT overexpression has been implicated in cisplatin resistance in several types of cancer. MT-3 was initially thought to be unresponsive to platinum drugs. However, we have recently shown a significant increase in chemoresistance to cisplatin due to MT-3 upregulation in neuroblastoma (Rodrigo et al., 2018). MT overexpression also predicts poor survival in bladder cancer patients. In patients treated with cisplatin-based chemotherapy, survival was significantly poorer when tumors expressed MT (Wulfing et al., 2007). Gumulec et al. reported that cisplatin-resistant prostate cancer cells displayed a significant increase in MT expression and decreased p53 and Bax (Gumulec et al., 2014a). These results, along with those of another study, may explain the events leading to the development of cisplatin resistance in prostate cancer (Gumulec et al., 2014a; Pekarik et al., 2013). Moreover, $M T-1 G$ was identified, via cDNA microarray, as a candidate cisplatin-resistance-related gene for gastric cancer (Suganuma et al., 2003). In NSCLC cells, MT-1H overexpression was shown to promote cisplatin resistance by decreasing the induction of apoptosis (Hou et al., 2009). Interestingly, an analysis found significantly higher serum MT levels in 25 patients with testicular cancer than in healthy 
1 volunteers, and furthermore, a significant amount of platinum was bound to proteins in the

2 fraction of MT elution (Tariba et al., 2015).

3 The treatment of prostate cancer cells with $\mathrm{Zn}^{++}$was found to increase MT expression, which

4 is significantly associated with resistance to cisplatin chemotherapy (Smith et al., 2006).

5 Other studies have shown that the elevation of MTs may be one mechanism of cisplatin

6 resistance in ovarian carcinoma (Cheng et al., 2006; Surowiak et al., 2005; Woolston et al., 2010). Elevated MT expression in ovarian cancers treated with cisplatin-based regimens was reported as an unfavorable prognostic factor for this treatment regimen (Surowiak et al., 2007). MTs were also found to be stably expressed at increased levels in cisplatin-resistant ovarian cancer cell lines compared with their cisplatin-sensitive counterparts (Kawahara et al., 2019).

The repeated administration of cisplatin as a treatment for human bladder tumors is known to exert lethal and renal toxicities (Li et al., 2016b). Bismuth pretreatment effectively prevented cisplatin toxicity without affecting its antitumor activity against human bladder tumors. MT levels induced by increasing the dose of bismuth in the kidneys maintained their substantially high levels during the treatment (Kondo et al., 1992). These data strongly suggest a promising protocol for chemotherapy using cisplatin with bismuth-based compounds - tissue-specific MT inducers that display very low untoward toxicity - against advanced bladder cancer. In addition, Chang et $a l$. showed that bismuth $\mathrm{Zn}^{++}$citrate potentially reduced cisplatin-induced toxicity without compromising the anticancer effect through enhanced expression of MTs (Chan et al., 2019).

Oxaliplatin and carboplatin derivatives of cisplatin have a similar mechanism of action but differ in terms of structure and toxicity. Previously, it has been observed that the intracellular mechanisms by which cells become resistant to carboplatin involve increased drug detoxification by the thiol groups of MTs and improved tolerance to nuclear damage, leading 
to a concomitant reduction in apoptosis and reduced accumulation of intracellular carboplatin (Kukacka et al., 2008; Wheate et al., 2010). The examination of MT expression in tissue biopsy specimens from HCC patients was shown to be useful in predicting the therapeutic effect of carboplatin (Endo et al., 2004).

Oxaliplatin, similar to other platinum-based compounds, exerts its cytotoxic effect mostly through DNA damage (Cao et al., 2020; Durmus et al., 2016; Ferreira et al., 2016; Hosseini et al., 2019; Leonetti et al., 2019b; Mokady and Meiri, 2015; Wijdeven et al., 2016). Cancer cell apoptosis is induced by the formation of DNA lesions, arrest of DNA replication, inhibition of transcription, and triggering of immunologic reactions (Alcindor and Beauger, 2011). Using novel strategies, Arriaga et al. showed that MT induction and $\mathrm{Zn}$ administration were feasible to sensitize CRC cells to oxaliplatin (Arriaga et al., 2014). Wong et al. demonstrated the ability of $M T-1 A$ to counteract transition metal complexes with cisplatin, emphasizing the detrimental role of MTs as a major player in the reduced effectiveness of metal-based drugs (Wong and Stillman, 2018).

Heptaplatin is a new platinum derivative gaining interest for its anticancer activity against cisplatin-resistant cancer cell lines (Xu and Wang, 2016). Interestingly, gastric cancer cell lines express different basal MT mRNA levels (Soo et al., 2011). Moreover, DNA hypomethylation was proposed to be responsible for the higher basal MT-2 mRNA levels in the cisplatin-resistant tumor cell lines. Choi et al. showed reduced cytotoxicity of cisplatin and carboplatin but not heptaplatin following MT induction with Zn. Heptaplatin was more efficient than both cisplatin and carboplatin against cisplatin-resistant gastric cancer cell lines and MT-overexpressing cell lines (Choi et al., 2004). Despite the absence of correlations between MT overexpression and platinum-drug resistance in some types of malignant cancers (Gansukh et al., 2013; Tuzel et al., 2015), most studies corroborated that elevated levels of MTs may be a plausible mechanism of cisplatin resistance in cancer. 


\subsection{MTs and chemoresistance to anthracyclines}

Anthracyclines are anticancer drugs that were originally derived from Streptomyces bacteria. Their antitumor activity was established in the 1960s. The four most common anthracyclines are Dox, daunorubicin, epirubicin and idarubicin (Marinello et al., 2018).

Dox is the lead compound of the anthracycline family. Cardiotoxicity limits anthracycline dosing, and despite improved cancer patient outcomes, the cancer survivors are subject to increased cardiovascular morbidity and mortality. The basic mechanisms of cardiotoxicity may involve direct pathways for ROS generation and topoisomerase II inhibition as well as other indirect pathways (McGowan et al., 2017). In this respect, it has been previously shown that cardiomyocyte-targeted deletion of the TOP $2 B$ gene protected cardiomyocytes from Doxmediated double-strand DNA breaks and transcriptome alterations, both of which underlie defective mitochondrial biogenesis and ROS generation (Zhang et al., 2012). Moreover, cardiomyocyte-targeted deletion of $T O P 2 B$ protected mice from Dox-induced progressive heart failure, indicating that Dox-induced cardiotoxicity is mediated via topoisomerase-II $\beta$ in cardiomyocytes.

Studies using transgenic mice with high levels of antioxidants such as MTs, specifically in the heart, have demonstrated that elevated cardiac antioxidant defense leads to decreased anthracycline cardiotoxicity. Positive correlations between histopathological lesions, apoptosis and MT expression were observed by Chmielewska et al. (Chmielewska et al., 2015). The results suggested that MT expression had protective and anti-apoptotic effects in renal proximal tubular cells under Dox treatment. MT-dependent protection against anthracycline-induced cardiotoxicity is related to its anti-apoptotic effects achieved by inhibiting both p38-MAPK-mediated and mitochondrial cytochrome c release-mediated apoptotic signaling (Kang, 2007). MT-2 downregulation in MCF-7 cells resulted in increased chemosensitivity of these cells to Dox (Kepinska et al., 2018). Another study has shown that 
1 cardiac-specific MT-overexpressing transgenic mice are highly resistant to acute

cardiotoxicity induced by Dox (Sun et al., 2001). In addition, MT-3 overexpression attenuated the effect of Dox on cell proliferation pathways in metastatic prostate cancer cell lines (Juang et al., 2013). The reduced cytotoxic effect of Dox in MTs overexpressing cardiomyocytes was correlated with the inhibition of lipid peroxidation induced by the drug (Wang and Kang, 1999). MT overexpression protected against Dox-induced inhibition of PGC-1 $\alpha$, a key regulator of mitochondrial biogenesis, and its downstream factors, including mitochondrial transcription factor A (Guo et al., 2014). Heger et al. showed in an exhaustive bibliographic review that MTs, as scavengers of ROS, regulated anthracycline chemoresistance in cancer and can also be used as a new cardioprotective therapeutic agent (Heger et al., 2016). In conclusion, elevated MT levels confer chemoresistance to anthracycline cytotoxicity through a mechanism involving the anti-apoptotic action of MTs. The MT redox cycle and $\mathrm{Zn}^{++}$ homeostasis most likely constitute the MT-involved antioxidant defense.

\subsection{MTs and resistance to tyrosine kinase inhibitors (TKIs)}

TKIs are a class of chemotherapeutic agents that inhibit or block one or more of the protein tyrosine kinases. TKIs are a family of small molecules or peptides with the ability to inhibit either cytosolic or receptor tyrosine kinases (Leonetti et al., 2019a; Roskoski, 2020). Many TKIs have been developed and approved across a wide range of tumor types to determine the critical roles of tyrosine kinases in regulating cellular signaling and tumor growth in patients (Gillis and McLeod, 2016). Inhibition by this class of cytotoxic agents is mediated through direct competition for ATP binding in the tyrosine kinase domain (genistein, lavendustin, imatinib, erlotinib, gefitinib, sorafenib), allosteric inhibition of tyrosine kinases (lavendustin A), inhibition of ligand binding to receptor tyrosine kinases (ecetuximab), inhibition of tyrosine kinase interaction with other proteins, or destabilization of the tyrosine kinase 
1 (herbimycin A and radicicol) (Reeves, 2016). However, acquired resistance of TKIs to

2 targeted therapies inevitably occurs (Camidge et al., 2014).

3 Sorafenib was originally identified as an inhibitor of multiple oncogenic kinases and remains

4 the only approved systemic therapy for advanced HCC. The antitumor efficiency of sorafenib

5 correlates with the inhibition of the Ser/Thr kinase Raf and several receptor tyrosine kinases,

6 including VEGFR and EGFR (Siegel et al., 2010). Currently, there is a lack of articles

7 regarding the MT mechanism in sorafenib-resistant cancers. However, two studies demonstrated that $M T-1 G$ and $M T-1 H$ isoforms act as tumor suppressors in HCC development

(Zeng et al., 2018; Zheng et al., 2017). Sun et al. demonstrated that upregulated $M T-1 G$ expression protects $\mathrm{HCC}$ cells from sorafenib and facilitates cancer progression by inhibiting lipid peroxidation-mediated ferroptosis. Thus, the modulation of $M T-1 G$ expression is a potential therapeutic strategy to overcome acquired resistance to sorafenib in cancer (Sun et al., 2016). Genes of the MT-1 family are also induced in the HCC cell line Huh7 upon exposure to sorafenib. Houessinon et al. examined the clinical relevance of characterizing the regulation of $M T-1 G$ in five tumor explants prepared from surgical HCC samples. The protein levels of MT-1 increased in the serum of HCC patients receiving sorafenib (Houessinon et al., 2016). The mRNA expression and protein expression of $M T-1 G$ are both markedly induced by sorafenib but not by other clinically relevant protein kinase inhibitors (e.g., erlotinib, gefitinib, tivantinib, vemurafenib, selumetinib, imatinib, masitinib, and ponatin). However, Pérez-Gutiérrez et al. showed that the differences in P-glycoprotein and MT expression could help to explain the observed response to systemic imatinib chemotherapy in gastrointestinal stromal tumors and leiomyosarcomas (Perez-Gutierrez et al., 2007).

\subsection{MTs and resistance to mitomycin C}

Mitomycin C, a potent DNA cross-linker, is one of the most commonly used agents in bladder cancer and has limited side effects. Specifically, intravesical instillation of mitomycin C 
1 following a transurethral resection of a bladder tumor constitutes a standard treatment

2 modality in the management of superficial transitional cell carcinoma of the urinary bladder.

3 However, MT overexpression predicts the resistance of superficial transitional cell carcinoma

4 of the bladder to intravesical mitomycin C therapy (Lynn et al., 2003). Another study

5 suggested that cross-resistance to cisplatin and carboplatin in a mitomycin C-resistant human

6 bladder cancer cell line may be due to the overexpression of MT-2-encoding mRNA (Singh et 7 al., 1995).

\subsection{MTs and resistance to other anticancer drugs}

Gemcitabine is a chemotherapeutic drug used for the treatment of NSCLC. MTs were highly associated with the sensitivity of gemcitabine in NSCLC (Chunhong et al., 2018). Overexpression of the MT-1G isoform sensitized CRC cell lines to the chemotherapeutic agent 5-fluorouracil in combination with oxaliplatin, in part through enhancing p53 and

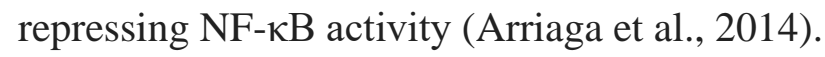

Irinotecan, a camptothecin derivative, is a DNA topoisomerase I inhibitor that is active against gastric cancer tumors (Chun et al., 2004b). Chun et al. suggested that irinotecaninduced upregulation of $M T-1 X$ might be associated with irinotecan resistance in patients with gastric cancer (Chun et al., 2004a).

Several clinical trials have shown gallium nitrate to be an active agent in the treatment of lymphoma. MT expression contributed to the development of gallium drug resistance. Gallium nitrate induced MT-2 and ZnT-1 expression in lymphoma cells. A role for MTs in modulating the antineoplastic activity of gallium was confirmed by showing that the induction of MT expression by $\mathrm{Zn}^{++}$provided partial protection against the cytotoxicity of gallium and that the level of endogenous MTs in lymphoma cell lines correlated with their sensitivity to gallium nitrate (Yang and Chitambar, 2008; Yang et al., 2007).

\section{Conclusions and future perspectives}


1 Cancer remains a major cause of mortality worldwide. Currently, drug resistance in cancer is the foremost threat to curative therapeutics. MTs contribute to the development of drug resistance through a variety of mechanisms in many types of cancers. MTs are proteins with an inexhaustible spectrum of biological functions. Despite their importance for the physiology of healthy cells, MTs also play a substantial role in various aspects of human malignancies. These proteins have functions such as metal ion homeostasis and detoxification, antioxidation against reactive oxygen species, protection against DNA damage, and the regulation of cell growth, proliferation, angiogenesis, and apoptosis. This review article shows that many independent groups of investigators found direct and indirect correlations between MTs and chemoresistance.

In addition to ROS detoxification, MT-drug interactions can be mediated directly in the case of metals (e.g., platinum in cisplatin and gallium in gallium nitrate) or mediated by $\mathrm{Zn}$ homeostasis (e.g., by controlling p53 DNA-binding domain folding) or by neutralizing reactive drug intermediates via MT sulfhydryl oxidation (e.g., the semiquinone form of Dox and the mitosene form of mitomycin C). Tyrosine kinase inhibitors serve as an alternative and indirect mechanism of resistance through MT expression modulation.

A great deal of research remains to be performed to fully unravel the molecular roles of MTs in this aspect. These future studies should focus on elucidating the distinct functions of individual MT isoforms, which could be useful not only for improved diagnostics but also as bona fide druggable targets for precision cancer therapy (or for combination therapy). Some insights were also noted regarding the usefulness of combining alternative compounds (e.g., bismuth-based compounds with cisplatin) for modulating MT activity, thus reducing drug toxicity without compromising anticancer effects. In addition, exploration of the regulatory mechanisms responsible for the expression of MT isoforms might provide substantial insights into their importance in cancer biology and therapeutics. In this review, we have shown MTs 
1 as molecular players that change sides once carcinogenesis occurs. The identification of that

2 upstream molecular switch is surely connected with the transcriptional regulation of MT

3 isoforms, and it is possible that various scenarios can arise for different types of cancer. In-

4 depth knowledge on the regulation of MTs may bring hope for overcoming chemoresistance

5 in cancer.

\section{$6 \quad$ Funding}

7 This research was funded by the European Research Council (ERC) under the European

8 Union's Horizon 2020 research and innovation programme (grant agreement no. 759585).

9 This research was carried out under the projects DFG-GACR (reg. no. 19-13766J) and 10 CEITEC 2020 (LQ1601) with financial support from the Ministry of Education, Youth and

11 Sports of the Czech Republic under the National Sustainability Programme II and National

12 Sustainability Programme I (grant no. LO1415).

\section{Declaration of Competing Interests}

14 The authors declare no conflicts of interest. 


\section{References}

P. Adam, S. Krizkova, Z. Heger, P. Babula, V. Pekarik, M. Vaculovicova, C.M. Gomez, R. Kizek and V. Adam, Metallothioneins in prion- and amyloid-related diseases, J. Alzheimers Dis. 51 (2016), pp. 637-656.

A.R. Aikins, S.-W. Hong, H.-J. Kim, C.-H. Yoon, J.-H. Chung, M.J. Kim and C.-W. Kim, Extremely low-frequency electromagnetic field induces neural differentiation of hBM-MSCs through regulation of (Zn)-metallothionein-3, Bioelectromagnetics 38 (2017), pp. 364-373.

T. Alcindor and N. Beauger, Oxaliplatin: a review in the era of molecularly targeted therapy, Curr. Oncol. 18 (2011), pp. 18-25.

L. Andrei, S. Kasas, I. Ochoa G., T. Stanković, M. Suárez Korsnes, R. Vaclavikova, Y.G. Assaraf and M. Pešić, Advanced technological tools to study multidrug resistance in cancer, Drug Resist. Updat. 48 (2020), pp. 1-19.

P.A. Andrews, M.P. Murphy and S.B. Howell, Metallothionein-mediated cisplatin resistance in human ovarian-carcinoma cells, Cancer Chemother. Pharmacol. 19 (1987), pp. 149-154. J.M. Arriaga, A.I. Bravo, J. Mordoh and M. Bianchini, Metallothionein 1G promotes the differentiation of HT-29 human colorectal cancer cells, Oncol. Rep. 37 (2017), pp. 26332651.

J.M. Arriaga, A. Greco, J. Mordoh and M. Bianchini, Metallothionein $1 \mathrm{G}$ and zinc sensitize human colorectal cancer cells to chemotherapy, Mol. Cancer Ther. 13 (2014), pp. 1369-1381.

E. Artells, O. Palacios, M. Capdevila and S. Atrian, In vivo-folded metal-metallothionein 3 complexes reveal the $\mathrm{Cu}$-thionein rather than $\mathrm{Zn}$-thionein character of this brain-specific mammalian metallothionein, FEBS J 281 (2014a), pp. 1659-1678.

E. Artells, O. Palacios, M. Capdevila and S. Atrian, In vivo-folded metal-metallothionein 3 complexes reveal the $\mathrm{Cu}$-thionein rather than $\mathrm{Zn}$-thionein character of this brain-specific mammalian metallothionein, FEBS J. 281 (2014b), pp. 1659-1678.

S. Atrian and M. Capdevila, Metallothionein-protein interactions, Biomol. Concepts 4 (2013), pp. 143-160.

P. Babula, M. Masarik, V. Adam, T. Eckschlager, M. Stiborova, L. Trnkova, H. Skutkova, I. Provaznik, J. Hubalek and R. Kizek, Mammalian metallothioneins: properties and functions, Metallomics 4 (2012), pp. 739-750.

M. Bar-Zeev, Y.D. Livney and Y.G. Assaraf, Targeted nanomedicine for cancer therapeutics: Towards precision medicine overcoming drug resistance, Drug Resist. Updat. 31 (2017), pp. 15-30.

A.K. Basu, DNA damage, mutagenesis and cancer, Int. J. Mol. Sci. 19 (2018), pp. 1-13.

B.H. Bay, R.X. Jin, J.X. Huang and P.H. Tan, Metallothionein as a prognostic biomarker in breast cancer, Exp. Biol. Med. 231 (2006), pp. 1516-1521.

A. Bieniek, B. Pula, A. Piotrowska, M. Podhorska-Okolow, A. Salwa, M. Koziol and P. Dziegiel, Expression of metallothionein I/II and Ki-67 antigen in various histological types of basal cell carcinoma, Folia Histochem. Cyto. 50 (2012), pp. 352-357.

M. Billaud, J.C. Hill, T.D. Richards, T.G. Gleason and J.A. Phillippi, Medial hypoxia and adventitial vasa vasorum remodeling in human ascending aortic aneurysm, Front. Cardiovasc. Med. 5 (2018), pp. 1-15.

A. Bizon, K. Jedryczko and H. Milnerowicz, The role of metallothionein in oncogenesis and cancer treatment, Postep. Hig. Med. Dosw. 71 (2017), pp. 98-109.

P.C. Borges, R. Ribeiro, S.V. Cardoso, A.L.C. Berbet, A. Rocha, F.S. Espindola and A.M. Loyola, Metallothionein immunolocalization in actinic skin nonmelanoma carcinomas, Appl. Immunohistochem. 15 (2007), pp. 165-169.

M.T. Brazao-Silva, M.F.S. Rodrigues, A.L.A. Eisenberg, F.L. Dias, L.M. de Castro, F.D. Nunes, P.R. Faria, S.V. Cardoso, A.M. Loyola and S. de Sousa, Metallothionein gene 
expression is altered in oral cancer and may predict metastasis and patient outcomes, Histopathol. 67 (2015), pp. 358-367.

G. Bredholt, M. Mannelqvist, I.M. Stefansson, E. Birkeland, T.H. Bo, A.M. Oyan, J. Trovik, K.H. Kalland, I. Jonassen, H.B. Salvesen, E. Wik and L.A. Akslen, Tumor necrosis is an important hallmark of aggressive endometrial cancer and associates with hypoxia, angiogenesis and inflammation responses, Oncotarget 6 (2015), pp. 39676-39691.

D.R. Camidge, W. Pao and L.V. Sequist, Acquired resistance to TKIs in solid tumours: learning from lung cancer, Nat. Rev. Clin. Oncol. 11 (2014), pp. 473-481.

X. Cao, J. Hou, Q. An, Y.G. Assaraf and X. Wang, Towards the overcoming of anticancer drug resistance mediated by p53 mutations, Drug Resist. Updat. 49 (2020), pp. 1-10.

S. Chan, R.M. Wang, K. Man, J. Nicholls, H.Y. Li, H.Z. Sun and G.C.F. Chan, A novel synthetic compound, bismuth zinc citrate, could potentially reduce cisplatin-induced toxicity without compromising the anticancer effect through enhanced expression of antioxidant protein, Transl. Oncol. 12 (2019), pp. 788-799.

H.H.W. Chen, W.C. Chen, Z.D. Liang, W.B. Tsai, Y. Long, I. Aiba, S.Q. Fu, R. Broaddus, J.S. Liu, L.G. Feun, N. Savaraj and M.T. Kuo, Targeting drug transport mechanisms for improving platinum-based cancer chemotherapy, Exp. Opin. Ther. Targets 19 (2015), pp. 1307-1317.

T.C. Cheng, G. Manorek, G. Samimi, X.J. Lin, C.C. Berry and S.B. Howell, Identification of genes whose expression is associated with cisplatin resistance in human ovarian carcinoma cells, Cancer Chemother. Pharmacol. 58 (2006), pp. 384-395.

M.G. Cherian, A. Jayasurya and B.H. Bay, Metallothioneins in human tumors and potential roles in carcinogenesis, Mutat. Res.-Fundam. Mol. Mech. Mutagen. 533 (2003), pp. 201-209.

J.K. Chesters and R. Boyne, Nature of the Zn2+ requirement for DNA-synthesis by 3T3 cells, Exp. Cell Res. 192 (1991), pp. 631-634.

J.K. Chesters, L. Petrie and H. Vint, Specificity and timing of the Zn-2+ requirement for DNA-synthesis by 3 T3 cells, Exp. Cell Res. 184 (1989), pp. 499-508.

J.L. Chin, D. Banerjee, S.A. Kadhim, T.E. Kontozoglou, P.J. Chauvin and M.G. Cherian, Metallothionein in testicular germ-cell tumors and drug-resistance - clinical correlation, Cancer 72 (1993), pp. 3029-3035.

M. Chmielewska, K. Symonowicz, B. Pula, T. Owczarek, M. Podhorska-Okolow, M. Ugorski and P. Dziegiel, Expression of metallothioneins I and II in kidney of doxorubicin-treated rats, Exp. Toxicol. Pathol. 67 (2015), pp. 297-303.

W.C. Cho, G. Jour and P.P. Aung, Role of angiogenesis in melanoma progression: Update on key angiogenic mechanisms and other associated components, Semin. Cancer Biol. 59 (2019), pp. 175-186.

C.H. Choi, Y.J. Cha, C.S. An, K.J. Kim, K.C. Kim, S.P. Moon, Z.H. Lee and Y.D. Min, Molecular mechanisms of heptaplatin effective against cisplatin-resistant cancer cell lines: less involvement of metallothionein, Cancer Cell Int. 4 (2004), pp. 1-12.

J.H. Chun, H.K. Kim, E. Kim, I.H. Kim, J.H. Kim, H.J. Chang, I.J. Choi, H.S. Lim, I.J. Kim, H.C. Kang, J.H. Park, J.M. Bae and J.G. Park, Increased expression of metallothionein is associated with irinotecan resistance in gastric cancer, Cancer Res. 64 (2004a), pp. 47034706.

J.H. Chun, H.K. Kim, J.S. Lee, J.Y. Choi, H.G. Lee, S.M. Yoon, I.J. Choi, K.W. Ryu, Y.W. Kim and J.M. Bae, Weekly irinotecan in patients with metastatic gastric cancer failing cisplatin-based chemotherapy, Jpn. J. Clin. Oncol. 34 (2004b), pp. 8-13.

L. Chunhong, L. Meiyan, L. Hailing, L. Wei, C. Li and D. Xiaoqun, Genes correlated with gemcitabine efficacy in non-small cell lung cancer, J. Cancer Sci. Ther. 10 (2018), pp. 1-4.

W.T. Cong, C. Niu, L.C. Lv, M.W. Ni, D.D. Ruan, L.S. Chi, Y. Wang, Q. Yu, K.G. Zhan, Y.H. Xuan, Y.H. Wang, Y. Tan, T.M. Wei, L. Cai and L.T. Jin, Metallothionein prevents age- 
associated cardiomyopathy via inhibiting NF-kappa B pathway activation and associated nitrative damage to 2-OGD, Antioxid. Redox. Signal. 25 (2016), pp. 936-952.

S. Coppola, I. Carnevale, E.H.J. Danen, G.J. Peters, T. Schmidt, Y.G. Assaraf and E. Giovannetti, A mechanopharmacology approach to overcome chemoresistance in pancreatic cancer, Drug. Resist. Updat. 31 (2017), pp. 43-51.

S. Dasari and P.B. Tchounwou, Cisplatin in cancer therapy: Molecular mechanisms of action, Eur. J. Pharmacol. 740 (2014), pp. 364-378.

J. Datta, S. Majumder, H. Kutay, T. Motiwala, W. Frankel, R. Costa, H.C. Cha, O.A. MacDougald, S.T. Jacob and K. Ghoshal, Metallothionein expression is suppressed in primary human hepatocellular carcinomas and is mediated through inactivation of CCAAT/enhancer binding protein alpha by phosphatidylinositol 3-kinase signaling cascade, Cancer Res. 67 (2007), pp. 2736-2746.

D.J. Deng, W. El-Rifai, J.F. Ji, B.D. Zhu, P. Trampont, J.Y. Li, M.F. Smith and S.M. Powel, Hypermethylation of metallothionein-3 CpG island in gastric carcinoma, Carcinogenesis 24 (2003), pp. 25-29.

F. Doz, N. Roosen and M.L. Rosenblum, Metallothionein and anticancer agents - the role of metallothionein in cancer-chemotherapy, J. Neurooncol. 17 (1993), pp. 123-129.

S. Durmus, S. van Hoppe and A.H. Schinkel, The impact of organic anion-transporting polypeptides (OATPs) on disposition and toxicity of antitumor drugs: Insights from knockout and humanized mice, Drug. Resist. Updat. 27 (2016), pp. 72-88.

M. Dutsch-Wicherek, T.J. Popiela, M. Klimek, L. Rudnicka-Sosin, L. Wicherek, J.P. Oudinet, J. Skladzien and R. Tomaszewska, Metallothionein stroma reaction in tumor adjacent healthy tissue in head and neck squamous cell carcinoma and breast adenocarcinoma, Neuroendocrinol. Lett. 26 (2005), pp. 567-574.

M. Dutsch-Wicherek, J. Sikora and R. Tomaszewska, The possible biological role of metallothionein in apoptosis, Front. Biosci. 13 (2008), pp. 4029-4038.

R. Dutta, D.A. Sens, S. Somji, M.A. Sens and S.H. Garrett, Metallothionein isoform 3 expression inhibits cell growth and increases drug resistance of PC-3 prostate cancer cells, Prostate 52 (2002), pp. 89-97.

P. Dziegiel, J. Forgacz, E. Suder, P. Surowiak, J. Kornafel and M. Zabel, Prognostic significance of metallothionein expression in correlation with $\mathrm{Ki}-67$ expression in adenocarcinomas of large intestine, Histol. Histopathol. 18 (2003), pp. 401-407.

P. Dziegiel, M. Podhorska-Okolow, W. Salwa-Zurawska, J. Zurawski, A. Wojnar and M. Zabel, Prognostic significance of augmented metallothionein (MT) expression correlated with Ki-67 antigen expression in selected soft tissue sarcomas, Anticancer Res. 24 (2004), pp. 3602-3602.

P. Dziegiel, B. Pula, C. Kobierzycki, M. Stasiolek and M. PodhorskaOkolow, Metallothioneins in normal and cancer cells. Metallothioneins in Normal and Cancer Cells (2016), pp. 1-117.

P. Dziegiel, W. Salwa-Zurawska, J. Zurawski, A. Wojnar and M. Zabel, Prognostic significance of augmented metallothionein (MT) expression correlated with Ki-67 antigen expression in selected soft tissue sarcomas, Histol. Histopath. 20 (2005), pp. 83-89.

M. Ebadi and P.L. Iversen, Metallothionein in carcinogenesis and cancer-chemotherapy, Gen. Pharmacol. 25 (1994), pp. 1297-1310.

M.P.A. Ebert, T. Gunther, J. Hoffmann, J. Yu, S. Miehlke, H.U. Schulz, A. Roessner, M. Korc and P. Malfertheiner, Expression of metallothionein II in intestinal metaplasia, dysplasia, and gastric cancer, Cancer Res. 60 (2000), pp. 1995-2001.

T. Eckschlager, V. Adam, J. Hrabeta, K. Figova and R. Kizek, Metallothioneins and cancer, Curr. Protein Pept. Sci. 10 (2009), pp. 360-375. 
S.L. El Sharkarvy and A.R.H. Farrag, Mean nuclear area and metallothionein expression in ductal breast tumors: Correlation with estrogen receptor status, Appl. Immunohistochem. 16 (2008), pp. 108-112.

E. Emri, K. Egervari, T. Varvolgyi, D. Rozsa, E. Miko, B. Dezso, I. Veres, G. Mehes, G. Emri and E. Remenyik, Correlation among metallothionein expression, intratumoural macrophage infiltration and the risk of metastasis in human cutaneous malignant melanoma, J. Eur. Acad. Dermatol. Venereol. 27 (2013), pp. 320-327.

T. Endo, K. Haraguchi and M. Sakata, Renal toxicity in rats after oral administration of mercury-contaminated boiled whale livers marketed for human consumption, Arch. Environ. Con. Tox. 44 (2003), pp. 412-416.

T. Endo, M. Yoshikawa, M. Ebara, K. Kato, M. Sunaga, H. Fukuda, A. Hayasaka, F. Kondo, N. Sugiura and H. Saisho, Immunohistochemical metallothionein expression in hepatocellular carcinoma: relation to tumor progression and chemoresistance to platinum agents, $J$. Gastroenterol. Hepatol. 39 (2004), pp. 1196-1201.

D. Esteban-Fernandez, J.M. Verdaguer, R. Ramirez-Camacho, M.A. Palacios and M.M. Gomez-Gomez, Accumulation, fractionation, and analysis of platinum in toxicologically affected tissues after cisplatin, oxaliplatin, and carboplatin administration, J. Anal. Tox. 32 (2008), pp. 140-146.

W.J. Faller, M. Rafferty, S. Hegarty, G. Gremel, D. Ryan, M.F. Fraga, M. Esteller, P.A. Dervan and W.M. Gallagher, Metallothionein 1E is methylated in malignant melanoma and increases sensitivity to cisplatin-induced apoptosis, Melanoma Res. 20 (2010), pp. 392-400.

S.J.A. Felizola, Y. Nakamura, Y. Arata, K. Ise, F. Satoh, W.E. Rainey, S. Midorikawa, S. Suzuki and H. Sasano, Metallothionein-3 (MT-3) in the human adrenal cortex and its disorders, Endocr. Pathol. 25 (2014), pp. 229-235.

W. Feng, F.W. Benz, J. Cai, W.M. Pierce and Y.J. Kang, Metallothionein disulfides are present in metallothionein-overexpressing transgenic mouse heart and increase under conditions of oxidative stress, J. Biol. Chem. 281 (2006), pp. 681-687.

J.A. Ferreira, A. Peixoto, M. Neves, C. Gaiteiro, C.A. Reis, Y.G. Assaraf and L.L. Santos, Mechanisms of cisplatin resistance and targeting of cancer stem cells: Adding glycosylation to the equation, Drug Resist. Updat. 24 (2016), pp. 34-54.

M. Fic, B. Pula, K. Rogala and P. Dziegiel, Role of metallothionein expression in gastrointestinal cancers, Postepy Biol. Komorki 40 (2013), pp. 5-20.

A.-M. Florea and D. Büsselberg, Cisplatin as an Anti-Tumor Drug: Cellular Mechanisms of Activity, Drug Resistance and Induced Side Effects, Cancers 3 (2011), pp. 1351-1371.

J.A. Friedline, S.H. Garrett, S. Somji, J.H. Todd and D.A. Sens, Differential expression of the MT-1E gene in estrogen-receptor-positive and -negative human breast cancer cell lines, Am. J. Pathol. 152 (1998), pp. 23-27.

J. Fu, H.J. Lv, H.X. Guan, X.Y. Ma, M.J. Ji, N.Y. He, B.Y. Shi and P. Hou, Metallothionein $1 \mathrm{G}$ functions as a tumor suppressor in thyroid cancer through modulating the PI3K/Akt signaling pathway, BMC Cancer 13 (2013), pp. 1-13.

R.N. Gacche and Y.G. Assaraf, Redundant angiogenic signaling and tumor drug resistance, Drug Resist. Updat. 36 (2018), pp. 47-76.

G. Galizia, F. Ferraraccio, E. Lieto, M. Orditura, P. Castellano, V. Imperatore, G. La Manna, M. Pinto, F. Ciardiello, A. La Mura and F. De Vita, p27 downregulation and metallothionein overexpression in gastric cancer patients are associated with a poor survival rate, J. Surg. Oncol. 93 (2006), pp. 241-252.

L.M. Gallicchio, J.A. Flaws, B.A. Fowler and O.B. Ioffe, Metallothionein expression in invasive and in situ breast carcinomas, Cancer Detect. Prev. 29 (2005), pp. 332-337. 
T. Gansukh, P. Donizy, A. Halon, H. Lage and P. Surowiak, In Vitro analysis of the relationships between metallothionein expression and cisplatin sensitivity of non-small cellular lung cancer cells, Anticancer Res. 33 (2013), pp. 5255-5260.

N.K. Gillis and H.L. McLeod, The pharmacogenomics of drug resistance to protein kinase inhibitors, Drug Resist. Updat. 28 (2016), pp. 28-42.

Y. Golan, T. Kambe and Y.G. Assaraf, The role of the zinc transporter SLC30A2/ZnT2 in transient neonatal zinc deficiency, Metallomics 9 (2017), pp. 1352-1366.

A. Gomulkiewicz, M. Podhorska-Okolow, R. Szulc, Z. Smorag, A. Wojnar, M. Zabel and P. Dziegiel, Correlation between metallothionein (MT) expression and selected prognostic factors in ductal breast cancers, Folia Histochem. Cyto. 48 (2010), pp. 242-248.

N. Gonen and Y.G. Assaraf, Antifolates in cancer therapy: Structure, activity and mechanisms of drug resistance, Drug Resist. Updat. 15 (2012), pp. 183-210.

J. Gumulec, J. Balvan, M. Sztalmachova, M. Raudenska, V. Dvorakova, L. Knopfova, H. Polanska, K. Hudcova, B. Ruttkay-Nedecky, P. Babula, V. Adam, R. Kizek, M. Stiborova and M. Masarik, Cisplatin-resistant prostate cancer model: Differences in antioxidant system, apoptosis and cell cycle, Int. J. Oncol. 44 (2014a), pp. 923-933.

J. Gumulec, M. Masarik, S. Krizkova, M. Hlavna, P. Babula, R. Hrabec, A. Rovny, M. Masarikova, J. Sochor, V. Adam, T. Eckschlager and R. Kizek, Evaluation of alphamethylacyl-CoA racemase, metallothionein and prostate specific antigen as prostate cancer prognostic markers, Neoplasma 59 (2012), pp. 191-200.

J. Gumulec, M. Raudenska, V. Adam, R. Kizek and M. Masarik, Metallothionein Immunohistochemical cancer biomarker: A meta-analysis, PLoS One 9 (2014b), pp. 1-14.

J.B. Guo, Q. Guo, H.Q. Fang, L. Lei, T.F. Zhang, J. Zhao and S.Q. Peng, Cardioprotection against doxorubicin by metallothionein Is associated with preservation of mitochondrial biogenesis involving PGC-1 alpha pathway, Eur. J. Pharmacol. 737 (2014), pp. 117-124.

N. Habel, Z. Hamidouche, I. Girault, A. Patino-Garcia, F. Lecanda, P.J. Marie and O. Fromigue, Zinc chelation: a metallothionein 2A's mechanism of action involved in osteosarcoma cell death and chemotherapy resistance, Cell Death Dis. 4 (2013), pp. 1-10.

Y.C. Han, Z.L. Zheng, Z.H. Zuo, Y.P. Yu, R. Chen, G.C. Tseng, J.B. Nelson and J.H. Luo, Metallothionein $1 \mathrm{~h}$ tumour suppressor activity in prostate cancer is mediated by euchromatin methyltransferase 1, J. Pathol. 230 (2013), pp. 184-193.

D. Hanahan and R.A. Weinberg, Hallmarks of cancer: The next generation, Cell 144 (2011), pp. 646-674.

A. Hayden, J. Douglas, M. Sommerlad, L. Andrews, K. Gould, S. Hussain, G.J. Thomas, G. Packham and S.J. Crabb, The Nrf2 transcription factor contributes to resistance to cisplatin in bladder cancer, Urol. Oncol.-Semin. Ori. 32 (2014), pp. 806-814.

L.F. He, X.X. Fan, Y.R. Li, M.M. Chen, B. Cui, G.Q. Chen, Y.L. Dai, D.Z. Zhou, X.T. Hu and H. Lin, Overexpression of zinc finger protein 384 (ZNF 384), a poor prognostic predictor, promotes cell growth by upregulating the expression of Cyclin D1 in Hepatocellular carcinoma, Cell Death Dis. 10 (2019), pp. 1-12.

Z. Heger, M.A.M. Rodrigo, S. Krizkova, B. Ruttkay-Nedecky, M. Zalewska, E.M.P. del Pozo, A. Pelfrene, B. Pourrut, M. Stiborova, T. Eckschlager, G. Emri, R. Kizek and V. Adam, Metallothionein as a scavenger of free radicals - New cardioprotective therapeutic agent or initiator of tumor chemoresistance?, Curr. Drug Targets 17 (2016), pp. 1438-1451.

J.G. Hengstler, H. Pilch, M. Schmidt, H. Dahlenburg, J. Sagemuller, I. Schiffer, F. Oesch, P.G. Knapstein, B. Kaina and B. Tanner, Metallothionein expression in ovarian cancer in relation to histopathological parameters and molecular markers of prognosis, Int. J. Cancer 95 (2001), pp. 121-127. 
R. Henrique, C. Jeronimo, M.O. Hoque, S. Nomoto, A.L. Carvalho, V.L. Costa, J. Oliveira, M.R. Teixeira, C. Lopes and D. Sidransky, MT1G hypermethylation is associated with higher tumor stage in prostate cancer, Cancer Epidemiol. Biomark. Prev. 14 (2005), pp. 1274-1278. N. Hirako, H. Nakano and S. Takahashi, A PU.1 suppressive target gene, metallothionein 1G, inhibits retinoic acid-induced NB4 cell differentiation, PLoS One 9 (2014), pp. 1-12.

Y. Hishikawa, S. Abe, S. Kinugasa, H. Yoshimura, N. Monden, M. Igarashi, M. Tachibana and N. Nagasue, Overexpression of metallothionein correlates with chemoresistance to cisplatin and prognosis in esophageal cancer, Oncology 54 (1997), pp. 342-347.

J.G. Hoey, S.H. Garrett, M.A. Sens, J.H. Todd and D.A. Sens, Expression of MT-3 mRNA in human kidney, proximal tubule cell cultures, and renal cell carcinoma, Toxicol. Lett. 92 (1997), pp. 149-160.

E.S. Hosseini, M.A. Zarei, S. Babashah, R.N. Sistani, M. Sadeghizadeh, H.H. Kashani, J.A. Mahabadi, F. Izadpanah, M.A. Atlasi and H. Nikzad, Studies on combination of oxaliplatin and dendrosomal nanocurcumin on proliferation, apoptosis induction, and long non-coding RNA expression in ovarian cancer cells, Cell. Biol. Toxicol. 35 (2019), pp. 247-266.

X.F. Hou, Q.X. Fan, L.X. Wang and S.X. Lu, Role of metallothionein $1 \mathrm{~h}$ in cisplatin resistance of non-small cell lung cancer cells, Chinese J. Cancer Res. 21 (2009), pp. 247-254.

X.F. Hou, L.P. Xu, H.Y. Song, S. Li, C. Wu and J.F. Wang, ECRG2 enhances the anti-cancer effects of cisplatin in cisplatin-resistant esophageal cancer cells via upregulation of p53 and downregulation of PNCA, World J. Gastroenterol. 23 (2017), pp. 1796-1803.

A. Houessinon, C. Franois, C. Sauzay, C. Louandre, G. Mongelard, C. Godin, S. Bodeau, S. Takahashi, Z. Saidak, L. Gutierrez, J.M. Regimbeau, N. Barget, J.C. Barbare, N. Ganne, B. Chauffert, R. Coriat and A. Galmiche, Metallothionein-1 as a biomarker of altered redox metabolism in hepatocellular carcinoma cells exposed to sorafenib, Mol. Cancer 15 (2016), pp. 1-10.

K. Inoue, H. Takano, T. Kaewamatawong, A. Shimada, J. Suzuki, R. Yanagisawa, S. Tasaka, A. Ishizaka and M. Satoh, Role of metallothionein in lung inflammation induced by ozone exposure in mice, Free Radic. Biol. Med. 45 (2008), pp. 1714-1722.

J.I. Izawa, M. Moussa, M.G. Cherian, G. Doig and J.L. Chin, Metallothionein expression in renal cancer, Urology 52 (1998), pp. 767-772.

A.M.L. Janssen, W. van Duijn, M.M. Oostendorp-van de Ruit, L. Kruidenier, C.B. Bosman, G. Griffioen, C. Lamers, J. van Krieken, C.J.H. van de Velde and H.W. Verspaget, Metallothionein in human gastrointestinal cancer, J. Pathol. 192 (2000), pp. 293-300.

A. Jayasurya, B.H. Bay, W.M. Yap, N.G. Tan and B.K.H. Tan, Proliferative potential in nasopharyngeal carcinoma: correlations with metallothionein expression and tissue zinc levels, Carcinogenesis 21 (2000), pp. 1809-1812.

R.X. Jin, B.H. Bay, V.T.K. Chow and P.H. Tan, Metallothionein 1F mRNA expression correlates with histological grade in breast carcinoma, Breast Cancer Res. Treat. 66 (2001), pp. 265-272.

R.X. Jin, V.T.K. Chow, P.H. Tan, S.T. Dheen, W. Duan and B.H. Bay, Metallothionein 2A expression is associated with cell proliferation in breast cancer, Carcinogenesis 23 (2002), pp. 81-86.

R.X. Jin, J.X. Huang, P.H. Tan and B.H. Bay, Clinicopathological significance of metallothioneins in breast cancer, Pathol. Oncol. Res. 10 (2004), pp. 74-79.

L. Jing, Y.L. Wu, J. Wu, J. Zhao, D.Y. Zuo and S.Q. Peng, Peroxiredoxins are involved in metallothionein protection from doxorubicin cardiotoxicity, Eur. J. Pharmacol. 659 (2011), pp. 224-232.

P.A. Jones and S.B. Baylin, The epigenomics of cancer, Cell 128 (2007), pp. 683-692. 
H.H. Juang, L.C. Chung, H.C. Sung, T.H. Feng, Y.H. Lee, P.L. Chang and K.H. Tsui, Metallothionein 3: An androgen-upregulated gene enhances cell invasion and tumorigenesis of prostate carcinoma cells, Prostate 73 (2013), pp. 1495-1506.

D. Juarez-Rebollar, C. Rios, C. Nava-Ruiz and M. Mendez-Armenta, Metallothionein in brain disorders, Oxid. Med. Cell. Longev. 2017 (2017), pp. 1-12.

Y.J. Kang, Antioxidant defense against anthracycline cardiotoxicity by metallothionein, Cardiovasc. Toxicol. 7 (2007), pp. 95-100.

A.V. Karotki and M. Vasak, Reaction of human metallothionein-3 with cisplatin and transplatin, J. Biol. Inorg. Chem. 14 (2009), pp. 1129-1138.

B. Kawahara, S. Ramadoss, G. Chaudhuri, C. Janzen, S. Sen and P.K. Mascharak, Carbon monoxide sensitizes cisplatin-resistant ovarian cancer cell lines toward cisplatin via attenuation of levels of glutathione and nuclear metallothionein, J. Inorg. Biochem. 191 (2019), pp. 29-39.

S.L. Kelley, A. Basu, B.A. Teicher, M.P. Hacker, D.H. Hamer and J.S. Lazo, Overexpresssion of metallothionein confers resistance to anticancer drugs, Science 241 (1988), pp. 1813-1815. M. Kepinska, R. Kizek and H. Milnerowicz, Metallothionein and superoxide dismutaseantioxidative protein status in fullerene-doxorubicin delivery to MCF-7 human breast cancer cells, Int. J. Mol. Sci. 19 (2018), pp. 1-17.

E.K. Kim, M. Jang, M.J. Song, D. Kim, Y. Kim and H.H. Jang, Redox-mediated mechanism of chemoresistance in cancer cells, Antioxidants 8 (2019), pp. 1-18.

H.G. Kim, Y.P. Hwang and H.G. Jeong, Metallothionein-III induces HIF-1 alpha-mediated VEGF expression in brain endothelial cells, Biochem. Biophys. Res. Commun. 369 (2008), pp. 666-671.

H.G. Kim, J.Y. Kim, E.H. Han, Y.P. Hwang, J.H. Choi, B.H. Park and H.G. Jeong, Metallothionein-2A overexpression increases the expression of matrix metalloproteinase-9 and invasion of breast cancer cells, FEBS Lett. 585 (2011), pp. 421-428.

T. Kimura and T. Kambe, The functions of metallothionein and ZIP and ZnT transporters: an overview and perspective, Int. J. Mol. Sci. 17 (2016), p. 336.

C.D. Klaassen, J.S. Liu and S. Choudhuri, Metallothionein: an intracellular protein to protect against cadmium toxicity, Annu. Rev. Pharmacol. Toxicol. 39 (1999), pp. 267-294.

R.B. Klassen, K. Crenshaw, R. Kozyraki, P.J. Verroust, L. Tio, S. Atrian, P.L. Allen and T.G. Hammond, Megalin mediates renal uptake of heavy metal metallothionein complexes, Am. J. Physiol. Renal. Physiol. 287 (2004), pp. 393-403.

Y. Kondo, M. Satoh, N. Imura and M. Akimoto, Tissue-specific induction of metallothionein by bismuth as a promising protocol for chemotherapy with repeated administration of cisdiamminedichloroplatinum (II) against bladder-tumor, Anticancer Res. 12 (1992), pp. 23032308.

J. Kopecka, P. Trouillas, A.C. Gasparovic, E. Gazzano, Y.G. Assaraf and C. Riganti, Phospholipids and cholesterol: Inducers of cancer multidrug resistance and therapeutic targets, Drug Resist. Updat. 49 (2020), pp. 1-17.

S. Krizkova, V. Adam and R. Kizek, Study of metallothionein oxidation by using of chip CE, Electrophoresis 30 (2009a), pp. 4029-4033.

S. Krizkova, I. Fabrik, V. Adam, P. Hrabeta, T. Eckschlager and R. Kizek, Metallothionein - a promising tool for cancer diagnostics, Bratisl. Med. J. 110 (2009b), pp. 93-97.

S. Krizkova, M. Kepinska, G. Emri, T. Eckschlager, M. Stiborova, P. Pokorna, Z. Heger and V. Adam, An insight into the complex roles of metallothioneins in malignant diseases with emphasis on (sub)isoforms/isoforms and epigenetics phenomena, Pharm. Ter. 183 (2018), pp. 90-117. 
S. Krizkova, M. Ryvolova, J. Hrabeta, V. Adam, M. Stiborova, T. Eckschlager and R. Kizek, Metallothioneins and zinc in cancer diagnosis and therapy, Drug Metab. Rev. 44 (2012), pp. 287-301.

A. Krzeslak, E. Forma, P. Jozwiak, A. Szymczyk, B. Smolarz, H. Romanowicz-Makowska, W. Rozanski and M. Brys, Metallothionein 2A genetic polymorphisms and risk of ductal breast cancer, Clin. Exp. Med. 14 (2014), pp. 107-113.

J. Kukacka, H. Tesfaye, J. Malis, V. Adam, I. Fabrik, K. Kotaska, J. Stary, R. Kizek and R. Prusa, Carboblatin monitoring by flameless atomic absorption spectrophotometry and metallothionein levels in pediatric patients with solid tumors, Clin. Chem. 54 (2008), pp. 1111.

Y.H. Lai, C. Kuo, M.T. Kuo and H.H.W. Chen, Modulating chemosensitivity of tumors to platinum-based antitumor drugs by transcriptional regulation of copper homeostasis, Int. J. Mol. Sci. 19 (2018), pp. 1-18.

Y.Y. Lai, G. Yip and B.H. Bay, Genomic analysis in breast cancer cells after metallothionein2A silencing, Cancer Res. 70 (2010).

Y.Y. Lai, G.W.C. Yip and B.H. Bay, Targeting metallothionein for prognosis and treatment of breast cancer, Recent Patents Anti-Canc. Drug Discov. 6 (2011), pp. 178-185.

J.H. Lee, J.W. Chae, J.K. Kim, H.J. Kim, J.Y. Chung and Y.H. Kim, Inhibition of cisplatinresistance by RNA interference targeting metallothionein using reducible oligo-peptoplex, $J$. Control. Release 215 (2015), pp. 82-90.

K.F. Lee, K.M. Lau and S.M. Ho, Effects of cadmium on metallothionein-I and metallothionein-II mRNA expression in rat ventral, lateral, and dorsal prostatic lobes: Quantification by competitive RT-PCR, Toxicol. Appl. Pharmacol. 154 (1999), pp. 20-27.

A.I. Lehvy, G. Horev, Y. Golan, F. Glaser, Y. Shammai and Y.G. Assaraf, Alterations in ZnT1 expression and function lead to impaired intracellular zinc homeostasis in cancer. Cell Death Discov. (2019), pp. 1-12.

A. Leonetti, Y.G. Assaraf, P.D. Veltsista, B. El Hassouni, M. Tiseo and E. Giovannetti, MicroRNAs as a drug resistance mechanism to targeted therapies in EGFR-mutated NSCLC: Current implications and future directions, Drug Resist. Updat. 42 (2019a), pp. 1-11.

A. Leonetti, B. Wever, G. Mazzaschi, Y.G. Assaraf, C. Rolfo, F. Quaini, M. Tiseo and E. Giovannetti, Molecular basis and rationale for combining immune checkpoint inhibitors with chemotherapy in non-small cell lung cancer, Drug Resist. Updat. 46 (2019b), pp. 1-12. W. Li, H. Zhang, Y.G. Assaraf, K. Zhao, X.J. Xue, J.B. Xie, D.H. Yang and Z.S. Chen, Overcoming ABC transporter-mediated multidrug resistance: Molecular mechanisms and novel therapeutic drug strategies, Drug Resist. Updat. 27 (2016a), pp. 14-29.

X.X. Li, H.L. Wang, J. Wang, Y.Y. Chen, X.B. Yin, G.Y. Shi, H. Li, Z.Q. Hu and X.W. Liang, Emodin enhances cisplatin-induced cytotoxicity in human bladder cancer cells through ROS elevation and MRP1 downregulation, BMC Cancer 16 (2016b), pp. 1-10.

Z.K. Liu, Q.W. Ye, L.J. Wu, F. Gao, H.Y. Xie, L. Zhou, S.S. Zheng and X. Xu, Metallothionein 1 family profiling identifies MT1X as a tumor suppressor involved in the progression and metastastatic capacity of hepatocellular carcinoma, Mol. Carcinog. 57 (2018), pp. 1435-1444.

Y.D. Livney and Y.G. Assaraf, Rationally designed nanovehicles to overcome cancer chemoresistance, Adv. Drug. Deliv. Rev. 65 (2013), pp. 1716-1730.

N.N.K. Lynn, M.C. Howe, R.J. Hale, G.N. Collins and P.H. O'Reilly, Over expression of metallothionein predicts resistance of transitional cell carcinoma of bladder to intravesical mitomycin therapy, J. Urol. 169 (2003), pp. 721-723.

M. Malavolta, F. Orlando, F. Piacenza, R. Giacconi, L. Costarelli, A. Basso, G. Lucarini, E. Pierpaoli and M. Provinciali, Metallothioneins, longevity and cancer: Comment on 
"Deficiency of metallothionein-1 and-2 genes shortens the lifespan of the $129 / \mathrm{Sv}$ mouse strain", Exp. Gerontol. 73 (2016), pp. 28-30.

R. Maleckaite, A. Zalimas, A. Bakavicius, F. Jankevicius, S. Jarmalaite and K. Daniunaite, DNA methylation of metallothionein genes is associated with the clinical features of renal cell carcinoma, Oncol. Rep. 41 (2019), pp. 3535-3544.

J. Mao, H.X. Yu, C.J. Wang, L.H. Sun, W. Jiang, P.Z. Zhang, Q.Y. Xiao, D.B. Han, H. Saiyin, J.D. Zhu, T.Y. Chen, L.R. Roberts, H.J. Huang and L. Yu, Metallothionein MT1M is a tumor suppressor of human hepatocellular carcinomas, Carcinogenesis 33 (2012), pp. 25682577.

M. Margoshes and B.L. Vallee, A cadmium protein from equine kidney cortex, J. Am. Chem. Soc. 79 (1957), pp. 4813-4814.

F.M. Marikar, G. Jin, W. Sheng, D. Ma and Z. Hua, Metallothionein 2A an interactive protein linking phosphorylated FADD to NF-kappa B pathway leads to colorectal cancer formation, Chinese Clin. Oncol. 5 (2016), pp. 1-15.

J. Marinello, M. Delcuratolo and G. Capranico, Anthracyclines as topoisomerase II poisons: from early studies to new perspectives, Int. J. Mol. Sci. 19 (2018), pp. 1-18.

B. Masiulionyte, I. Valiulyte, A. Tamasauskas and D. Skiriute, Metallothionein genes are highly expressed in malignant astrocytomas and associated with patient survival, Sci. Rep. 9 (2019), pp. 1-7.

J. Mattern and M. Volm, Increased resistance to doxorubicin in human non-small cell lung carcinomas with metallothionein expression, Int. J. Oncol. 1 (1992), pp. 687-689.

W.G. McCluggage, P. Maxwell, P.W. Hamilton and B. Jasani, High metallothionein expression is associated with features predictive of aggressive behaviour in endometrial carcinoma, Histopathol. 34 (1999), pp. 51-55.

W.G. McCluggage, K. Strand and A. Abdulkadir, Immunohistochemical localization of metallothionein in benign and malignant epithelial ovarian tumors, Int. J. Gynecol. Cancer 12 (2002), pp. 62-65.

H.M. McGee, G.M. Woods, B. Bennett and R.S. Chung, The two faces of metallothionein in carcinogenesis: photoprotection against UVR-induced cancer and promotion of tumour survival, Phtochem. Photobiol. Sci. 9 (2010), pp. 586-596.

J.V. McGowan, R. Chung, A. Maulik, I. Piotrowska, J.M. Walker and D.M. Yellon, Anthracycline chemotherapy and cardiotoxicity, Cardiovasc. Drugs Ther. 31 (2017), pp. 6375.

R.V. McNeill, A.S. Mason, M.E. Hodson, J.W.F. Catto and J. Southgate, Specificity of the metallothionein-1 response by cadmium-exposed normal human urothelial cells, Int. J. Mol. Sci. 20 (2019), pp. 1-18.

A.T. Miles, G.M. Hawksworth, J.H. Beattie and V. Rodilla, Induction, regulation, degradation, and biological significance of mammalian metallothioneins, Crit. Rev. Biochem. Mol. Biol. 35 (2000), pp. 35-70.

D. Mitropoulos, A. Kyroudi-Voulgari, S.E. Theocharis, E. Serafetinides, E. Moraitis, A. Zervas and C. Kittas, Prognostic significance of metallothionein expression in renal cell carcinoma, World. J. Surg. Oncol. 3 (2005), pp. 1-5.

H. Miyashita and Y. Sato, Metallothionein 1 is a downstream target of vascular endothelial zinc finger 1 (VEZF1) in endothelial cells and participates in the regulation of angiogenesis, Endothelium-J. Endoth. 12 (2005), pp. 163-170.

D. Mokady and D. Meiri, RhoGTPases - A novel link between cytoskeleton organization and cisplatin resistance, Drug Resist. Updat. 19 (2015), pp. 22-32.

A. Moleirinho, J. Carneiro, R. Matthiesen, R.M. Silva, A. Amorim and L. Azevedo, Gains, losses and changes of function after gene duplication: study of the metallothionein family, PLoS One 6 (2011), pp. 1-9. 
N. Morellini, N. Giles, S. Rea, S. Dunlop, L. Beazley, A. West, M. Fear and F. Wood, Single administration of metallothionein-IIA enhances wound healing following burn injury, Wound Repair Regen. 18 (2010), pp. 60-60.

M. Moussa, D. Kloth, G. Peers, M.G. Cherian, J.V. Frei and J.L. Chin, Metallothionein expression in prostatic carcinoma: correlation with Gleason grade, pathologic stage, DNA content and serum level of prostate-specific antigen, Clin. Invest. Med. 20 (1997), pp. 371380 .

W.W. Nagel and B.L. Vallee, Cell-cycle regulation of metallothionein in human coloniccancer cells, Proc. Natl. Acad. Sci. U. S. A. 92 (1995), pp. 579-583.

A. Nguyen, Z. Jing, P.S. Mahoney, R. Davis, S.C. Sikka, K.C. Agrawal and A.B. AbdelMageed, In vivo gene expression profile analysis of metallothionein in renal cell carcinoma, Cancer Lett. 160 (2000), pp. 133-140.

G. Ohshio, T. Imamura, N. Okada, Z.H. Wang, K. Yamaki, T. Kyogoku, H. Suwa, H. Yamabe and M. Imamura, Immunohistochemical study of metallothionein in pancreatic carcinomas, J. Cancer Res. Clin. Oncol. 122 (1996), pp. 351-355.

S. Ono, Metallothionein is a potential therapeutic strategy for amyotrophic lateral sclerosis, Curr. Pharm. Des. 23 (2017), pp. 5001-5009.

Y.M. Pan, J.Q. Huang, R. Xing, X. Yin, J.T. Cui, W.M. Li, J. Yu and Y.Y. Lu, Metallothionein 2A inhibits NF-kappa B pathway activation and predicts clinical outcome segregated with TNM stage in gastric cancer patients following radical resection, J. Transl. Med. 11 (2013a), pp. 1-14.

Y.M. Pan, S.Y. Lin, R. Xing, M. Zhu, B.N. Lin, J.T. Cui, W.M. Li, J. Gao, L. Shen, Y.Y. Zhao, M.Z. Guo, J.M. Wang, J.Q. Huang and Y.Y. Lu, Epigenetic upregulation of metallothionein $2 \mathrm{~A}$ by diallyl trisulfide enhances chemosensitivity of human gastric cancer cells to docetaxel through attenuating NF-B activation, Antioxid. Redox. Signal. 24 (2016), pp. 839-854.

Y.M. Pan, R. Xing, J.T. Cui, W.M. Li and Y.Y. Lu, Clinicopathological significance of altered metallothionein 2A expression in gastric cancer according to Lauren's classification, Chinese Med. J. 126 (2013b), pp. 2681-2686.

M.W. Pankhurst, W. Bennett, M.T.K. Kirkcaldie, A.K. West and R.S. Chung, Increased circulating leukocyte numbers and altered macrophage phenotype correlate with the altered immune response to brain injury in metallothionein (MT) -I/II null mutant mice, $J$. Neuroinflammation 8 (2011), pp. 1-9.

M.O. Pedersen, A. Larsen, M. Stoltenberg and M. Penkowa, The role of metallothionein in oncogenesis and cancer prognosis, Prog. Histochem. Cytochem. 44 (2009), pp. 29-64.

V. Pekarik, J. Gumulec, M. Masarik, R. Kizek and V. Adam, Prostate cancer, miRNAs, metallothioneins and resistance to cytostatic drugs, Curr. Med. Chem. 20 (2013), pp. 534-544. M. Penkowa, J. Carrasco, M. Giralt, A. Molinero, J. Hernandez, I.L. Campbell and J. Hidalgo, Altered central nervous system cytokine-growth factor expression profiles and angiogenesis in metallothionein-I plus II deficient mice, J. Cerebr. Blood Flow Metab. 20 (2000), pp. 11741189.

S. Perez-Gutierrez, R. Gonzalez-Campora, J. Amerigo-Navarro, A. Beato-Moreno, M. Sanchez-Leon, M.J. Pareja Megia, J.A. Virizuela-Echaburu and A. Lopez-Beltran, Expression of p-glycoprotein and metallothionein in gastrointestinal stromal tumor and leiomyosarcomas. Clinical implications, Pathol. Oncol. Res. 13 (2007), pp. 203-208.

R.J. Person, E.J. Tokar, Y.Y. Xu, R. Orihuela, N.N.O. Ngalame and M.P. Waalkes, Chronic cadmium exposure in vitro induces cancer cell characteristics in human lung cells, Toxicol. Appl. Pharmacol. 273 (2013), pp. 281-288. 
B. Pula, T. Tazbierski, A. Zamirska, B. Werynska, A. Bieniek, J. Szepietowski, J. Rys, P. Dziegiel and M. Podhorska-Okolow, Metallothionein 3 expression in normal skin and malignant skin lesions, Pathol. Oncol. Res. 21 (2015), pp. 187-193.

M.T. Rahman, N. Haque, N.H. Abu Kasim and M. De Ley, Origin, function, and fate of metallothionein in human blood. In: B. Nilius, P. DeTombe, T. Gudermann, R. Jahn, R. Lill and O.H. Petersen, Editors, Reviews of Physiology, Biochemistry and Pharmacology, Springer-Verlag Berlin, Berlin (2017), pp. 41-62.

M. Raschke, I.R. Rowland, P.J. Magee and B.L. Pool-Zobel, Genistein protects prostate cells against hydrogen peroxide-induced DNA damage and induces expression of genes involved in the defence against oxidative stress, Carcinogenesis 27 (2006), pp. 2322-2330.

M. Raudenska, J. Gumulec, O. Podlaha, M. Sztalmachova, P. Babula, T. Eckschlager, V. Adam, R. Kizek and M. Masarik, Metallothionein polymorphisms in pathological processes, Metallomics 6 (2014), pp. 55-68.

M. Ravera, E. Gabano, M.J. McGlinchey and D. Osella, A view on multi-action Pt(IV) antitumor prodrugs, Inorganica Chim. Acta 492 (2019), pp. 32-47.

A. Rebillard, D. Lagadic-Gossmann and M.T. Dimanche-Boitrel, Cisplatin cytotoxicity: DNA and plasma membrane targets, Curr. Med. Chem. 15 (2008), pp. 2656-2663.

D. Reeves, Cytostatic agents-tyrosine kinase inhibitors utilized in the treatment of solid malignancies. In: S.D. Ray, Editor, Side Effects of Drugs Annual: A Worldwide Yearly Survey of New Data in Adverse Drug Reactions (2016), pp. 479-491.

N.A. Rezk, H.E. Zidan, M. Riad, W. Mansy and S.A. Mohamad, Metallothionein 2A expression and its relation to different clinical stages and grades of breast cancer in Egyptian patients, Gene 571 (2015), pp. 17-22.

C.R.R. Rocha, M.M. Silva, A. Quinet, J.B. Cabral-Neto and C.F.M. Menck, DNA repair pathways and cisplatin resistance: an intimate relationship, Clinics 73 (2018), pp. 1-10.

M.A.M. Rodrigo, S. Dostalova, H. Buchtelova, V. Strmiska, P. Michalek, S. Krizkova, A. Vicha, P. Jencova, T. Eckschlager, M. Stiborova, Z. Heger and V. Adam, Comparative gene expression profiling of human metallothionein-3 up-regulation in neuroblastoma cells and its impact on susceptibility to cisplatin, Oncotarget 9 (2018), pp. 4427-4439.

R. Roskoski, Properties of FDA-approved small molecule protein kinase inhibitors: A 2020 update, Pharm. Res. 152 (2020), pp. 1-15.

S. Roy, J. Gumulec, A. Kumar, M. Raudenska, M.H. Baig, H. Polanska, J. Balvan, M. Gupta, P. Babula, J. Odstrcilik, I. Choi, I. Provaznik and M. Masarik, The effect of benzothiazolone2 on the expression of metallothionein-3 in modulating Alzheimer's disease, Brain. Behav. 7 (2017), pp. 1-9.

S. Russi, H.K. Verma, S. Laurino, P. Mazzone, G. Storto, A. Nardelli, P. Zoppoli, G. Calice, F. La Rocca, A. Sgambato, V. Lucci, G. Falco and V. Ruggieri, Adapting and surviving: Intra and extra-cellular remodeling in drug-resistant gastric cancer cells, Int. J. Mol. Sci. 20 (2019), pp. 1-17.

B. Ruttkay-Nedecky, L. Nejdl, J. Gumulec, O. Zitka, M. Masarik, T. Eckschlager, M. Stiborova, V. Adam and R. Kizek, The role of metallothionein in oxidative stress, Int. J. Mol. Sci. 14 (2013), pp. 6044-6066.

M. Ryvolova, V. Adam and R. Kizek, Analysis of metallothionein by capillary electrophoresis, J. Chromatogr. A 1226 (2012), pp. 31-42.

L.H.T. Sakamoto, B. de Camargo, M. Cajaiba, F.A. Soares and A.L. Vettore, MT1G hypermethylation: A potential prognostic marker for hepatoblastoma, Pediatr. Res. 67 (2010), pp. 387-393.

F.A. Sampaio, L.M. Martins, C. Dourado, C.M.S. Revoredo, D.R. Costa-Silva, V.A. de Oliveira, F.A. Alves-Ribeiro and B.B. da Silva, A case-control study of metallothionein-1 expression in breast cancer and breast fibroadenoma, Sci. Rep. 9 (2019), pp. 1-5. 
A. Schuermann, C.S.M. Helker and W. Herzog, Metallothionein 2 regulates endothelial cell migration through transcriptional regulation of vegfc expression, Angiogenesis 18 (2015), pp. 463-475.

M.A. Sens, V. Gurel, S. Somji, S.H. Garrett and D.A. Sens, Metallothionein isoform 3 (MT3) inhibits growth and increases chemotherapeutic drug resistance of breast cancer cells, Modern Pathol. 15 (2002), pp. 51-51.

V.K. Shukla, N.C. Aryya, A. Pitale, M. Pandey, V.K. Dixit, C.D. Reddy and A. Gautam, Metallothionein expression in carcinoma of the gallbladder, Histopathol. 33 (1998), pp. 154157.

M.F. Si and J.H. Lang, The roles of metallothioneins in carcinogenesis, J. Hematol. Oncol. 11 (2018), pp. 1-20.

A.B. Siegel, S.K. Olsen, A. Magun and R.S. Brown, Sorafenib: Where do we go from here?, Hepatology 52 (2010), pp. 360-369.

S.V. Singh, B.H. Xu, J.P. Jani, E.O. Emerson, M.G. Beckes, C. Rihn, D. Scalamogna, N. Stemmler, S. Specht, K. Blanock, A. Katoh and V. Gupta, Mechanism of cross-resistance to cisplatin in a mitomycin C-resistant human bladder-cancer cell-line, Int. J. Cancer 61 (1995), pp. 431-436.

M.A. Skowron, M. Melnikova, J.G.H. van Roermund, A. Romano, P. Albers, J. Thomale, W.A. Schulz, G. Niegisch and M.J. Hoffmann, Multifaceted mechanisms of cisplatin resistance in long-term treated urothelial carcinoma cell lines, Int. J. Mol. Sci. 19 (2018), pp. $1-17$.

D.J. Smith, M. Jaggi, W. Zhang, A. Galich, C. Du, S.P. Sterrett, L.M. Smith and K.C. Balaji, Metallothioneins and resistance to cisplatin and radiation in prostate cancer, Urology 67 (2006), pp. 1341-1347.

E.T.L. Soo, C.T. Ng, G.W.C. Yip, C.Y. Koo, M.E. Nga, P.H. Tan and B.H. Bay, Differential expression of metallothionein in gastrointestinal stromal tumors and gastric carcinomas, Anat. Rec. 294 (2011), pp. 267-272.

K. Suganuma, T. Kubota, Y. Saikawa, S. Abe, Y. Otani, T. Furukawa, K. Kumai, H. Hasegawa, M. Watanabe, M. Kitajima, H. Nakayama and H. Okabe, Possible chemoresistance-related genes for gastric cancer detected by cDNA microarray, Cancer Sci. 94 (2003), pp. 355-359.

X.F. Sun, X.H. Niu, R.C. Chen, W.Y. He, D. Chen, R. Kang and D.L. Tang, Metallothionein$1 \mathrm{G}$ facilitates sorafenib resistance through inhibition of ferroptosis, Hepatology 64 (2016), pp. 488-500.

X.H. Sun, Z.X. Zhou and Y.J. Kang, Attenuation of doxorubicin chronic toxicity in metallothionein-overexpressing transgenic mouse heart, Cancer Res. 61 (2001), pp. 33823387.

P. Surowiak, V. Materna, B. Gyorffy, R. Matkowski, A. Wojnar, A. Maciejczyk, P. Paluchowski, P. Dziegiel, M. Pudelko, J. Kornafel, M. Dietel, G. Kristiansen, M. Zabel and H. Lage, Multivariate analysis of oestrogen receptor alpha, pS2, metallothionein and CD24 expression in invasive breast cancers, Br. J. Cancer 95 (2006), pp. 339-346.

P. Surowiak, V. Materna, I. Kaplenko, M. Spaczynski, M. Dietel, H. Lage and M. Zabel, Augmented expression of metallothionein and glutathione S-transferase pi as unfavourable prognostic factors in cisplatin-treated ovarian cancer patients, Virchows Arch. 447 (2005), pp. 626-633.

P. Surowiak, V. Materna, A. Maciejczyk, M. Pudelko, E. Markwitz, M. Spaczynski, M. Dietel, M. Zabel and H. Lage, Nuclear metallothionein expression correlates with cisplatin resistance of ovarian cancer cells and poor clinical outcome, Virchows Arch. 450 (2007), pp. 279-285. 
J.S. Suzuki, N. Nishimura, B.X. Zhang, Y. Nakatsuru, S. Kobayashi, M. Satoh and C. Tohyama, Metallothionein deficiency enhances skin carcinogenesis induced by 7,12dimethylbenz a anthracene and 12-O-tetradecanoylphorbol-13-acetate in metallothionein-null mice, Carcinogenesis 24 (2003), pp. 1123-1132.

Z. Szilagyi and C. Fenselau, Molecular dynamics simulation of metallothionein-drug complexes, Drug. Metab. Dispos. 28 (2000), pp. 174-179.

S. Takahashi, Molecular functions of metallothionein and its role in hematological malignancies, J. Hematol. Oncol. 5 (2012), pp. 1-8.

M. Takaishi, A. Shimada, J.S. Suzuki, M. Satoh and H. Nagase, Involvement of metallothionein (MT) as a biological protective factor against carcinogenesis induced by benzo a pyrene (B a P), J. Toxicol. Sci. 35 (2010), pp. 225-230.

B. Tanner, H. Pilch, M. Schmidt and J.G. Hengstler, Expression of metallothionein and glutathione in ovarian carcinomas, Geburtshilfe Frauenheilkd. 62 (2002), pp. 145-155.

X. Tao, J.M. Zheng, A.M. Xu, X.F. Chen and S.H. Zhang, Downregulated expression of metallothionein and its clinicopathological significance in hepatocellular carcinoma, Hepatol. Res. 37 (2007), pp. 820-827.

B. Tariba, T. Zivkovic, N. Krasnici, V.F. Marijic, M. Erk, M. Gamulin, M. Grgic and A. Pizent, Serum metallothionein in patients with testicular cancer, Cancer Chemother. Pharmacol. 75 (2015), pp. 813-820.

S. Taylor, E.P. Spugnini, Y.G. Assaraf, T. Azzarito, C. Rauch and S. Fais, Microenvironment acidity as a major determinant of tumor chemoresistance: Proton pump inhibitors (PPIs) as a novel therapeutic approach, Drug Resist. Updat. 23 (2015), pp. 69-78.

S.E. Theocharis, A.P. Margeli, J.T. Klijanienko and G.P. Kouraklis, Metallothionein expression in human neoplasia, Histopathol. 45 (2004), pp. 103-118.

N. Thirumoorthy, K.T.M. Kumar, A.S. Sundar, L. Panayappan and M. Chatterjee, Metallothionein: An overview, World J. Gastroenterol. 13 (2007), pp. 993-996.

N. Thirumoorthy, A.S. Sunder, K.T.M. Kumar, G.N.K. Ganesh and M. Chatterjee, A review of metallothionein isoforms and their role in pathophysiology, World. J. Surg. Oncol. 9 (2011), pp. 1-7.

C.D. Tran, R. Gobel and E.L. Symonds, Metallothionein expression in Helicobacter-infected pregnant mice and their fetuses and pups, Dig. Dis. Sci. 52 (2007), pp. 1527-1532.

E. Tuzel, K. Yorukoglu, E. Ozkara and Z. Kirkali, Association of metallothionein expression and clinical response to cisplatin based chemotherapy in testicular germ cell tumors, Cent. Eur. J. Urol. 68 (2015), pp. 45-50.

A. Viarengo, B. Burlando, N. Ceratto and I. Panfoli, Antioxidant role of metallothioneins: A comparative overview, Cell. Mol. Biol. 46 (2000), pp. 407-417.

A. Waeytens, M. De Vos and D. Laukens, Evidence for a potential role of metallothioneins in inflammatory bowel diseases, Mediators Inflamm. 2009 (2009), pp. 1-10.

R. Waller, M. Murphy, C.J. Garwood, L. Jennings, P.R. Heath, A. Chambers, F.E. Matthews, C. Brayne, P.G. Ince, S.B. Wharton and J.E. Simpson, Metallothionein-I/II expression associates with the astrocyte DNA damage response and not Alzheimer-type pathology in the aging brain, Glia 66 (2018), pp. 2316-2323.

G.W. Wang and Y.J. Kang, Inhibition of doxorubicin toxicity in cultured neonatal mouse cardiomyocytes with elevated metallothionein levels, J. Pharmacol. Exp. Ther. 288 (1999), pp. 938-944.

Z.G. Wang, Z.Q. Deng and G.Y. Zhu, Emerging platinum(IV) prodrugs to combat cisplatin resistance: from isolated cancer cells to tumor microenvironment, Dalton Transact. 48 (2019), pp. 2536-2544. 
H. Wei, M.M. Desouki, S. Lin, D. Xiao, R.B. Franklin and P. Feng, Differential expression of metallothioneins (MTs) 1, 2, and 3 in response to zinc treatment in human prostate normal and malignant cells and tissues, Mol. Cancer 7 (2008), pp. 1-11.

G. Weinlich, W. Bitterlich, V. Mayr, P.O. Fritsch and B. Zelger, Metallothioneinoverexpression as a prognostic factor for progression and survival in melanoma. A prospective study on 520 patients, Br. J. Dermatol. 149 (2003), pp. 535-541.

B. Werynska, B. Pula, B. Muszczynska-Bernhard, A. Piotrowska, A. Jethon, M. PodhorskaOkolow, P. Dziegiel and R. Jankowska, Correlation between expression of metallothionein and expression of Ki-67 and MCM-2 proliferation markers in non-small cell lung cancer, Anticancer Res. 31 (2011), pp. 2833-2839.

N.J. Wheate, S. Walker, G.E. Craig and R. Oun, The status of platinum anticancer drugs in the clinic and in clinical trials, Dalton Transact. 39 (2010), pp. 8113-8127.

B. Wierzowiecka, A. Gomulkiewicz, L. Cwynar-Zajac, M. Olbromski, J. Grzegrzolka, C. Kobierzycki, M. Podhorska-Okolow and P. Dziegiel, Expression of metallothionein and vascular endothelial growth factor isoforms in breast cancer cells, In Vivo 30 (2016), pp. 271278.

R.H. Wijdeven, B.X. Pang, Y.G. Assaraf and J. Neefjes, Old drugs, novel ways out: Drug resistance toward cytotoxic chemotherapeutics, Drug Resist. Updat. 28 (2016), pp. 65-81.

T.W. Wilhelmsen, P.A. Olsvik, B.H. Hansen and R.A. Andersen, Evidence for oligomerization of metallothioneins in their functional state, J. Chrom. A. 979 (2002), pp. 249-254.

D.L. Wong and M. Stillman, Destructive interactions of dirhodium (II) tetraacetate with $\beta$ metallothionein rh1a, Chem. Commun. 52 (2016), pp. 5698-5701.

D.L. Wong and M.J. Stillman, Capturing platinum in cisplatin: kinetic reactions with recombinant human apo-metallothionein 1a, Metallomics 10 (2018), pp. 713-721.

C.M. Woolston, S. Deen, A. Al-Attar, M. Shehata, S.Y. Chan and S.G. Martin, Redox protein expression predicts progression-free and overall survival in ovarian cancer patients treated with platinum-based chemotherapy, Free Radic. Biol. Med. 49 (2010), pp. 1263-1272.

C. Wu, C. Pot, L. Apetoh, T. Thalhamer, B. Zhu, G. Murugaiyan, S. Xiao, Y. Lee, M. Rangachari, N. Yosef and V.K. Kuchroo, Metallothioneins negatively regulate IL-27-induced type 1 regulatory T-cell differentiation, Proc. Natl. Acad. Sci. U. S. A. 110 (2013), pp. $7802-$ 7807.

C. Wulfing, H. van Ahlen, E. Eltze, H. Piechota, L. Hertle and K.W. Schmid, Metallothionein in bladder cancer: correlation of overexpression with poor outcome after chemotherapy, World J. Urol. 25 (2007), pp. 199-205.

W. Xu and D.C. Wang, Synthesis of novel heptaplatin derivatives and evaluation of their ability to inhibit proliferation of cancer cell lines, Russ. J. Gen. Chem. 86 (2016), pp. 939-943. D.W. Yan, J.W. Fan, Z.H. Yu, M.X. Li, Y.G. Wen, D.W. Li, C.Z. Zhou, X.L. Wang, Q. Wang, H.M. Tang and Z.H. Peng, Downregulation of metallothionein 1F, a putative oncosuppressor, by loss of heterozygosity in colon cancer tissue, Biochim. Biophys. Acta-Mol. Basis Dis. 1822 (2012), pp. 918-926.

M. Yang and C.R. Chitambar, Role of oxidative stress in the induction of metallothionein-2A and heme oxygenase- 1 gene expression by the antineoplastic agent gallium nitrate in human lymphoma cells, Free Radic. Biol. Med. 45 (2008), pp. 763-772.

M.Y. Yang, S.H. Kroft and C.R. Chitambar, Gene expression analysis of gallium-resistant and gallium-sensitive lymphoma cells reveals a role for metal-responsive transcription factor1 , metallothionein-2A, and zinc transporter-1 in modulating the antineoplastic activity of gallium nitrate, Mol. Cancer Ther. 6 (2007), pp. 633-643. 
X.L. Yap, H.Y. Tan, J.X. Huang, Y.Y. Lai, G.W.C. Yip, P.H. Tan and B.H. Bay, Overexpression of metallothionein predicts chemoresistance in breast cancer, J. Pathol. 217 (2009), pp. 563-570.

J. Youn, S.H. Hwang, Z.Y. Ryoo, M.A. Lynes, D.J. Paik, H.S. Chung and H.Y. Kim, Metallothionein suppresses collagen-induced arthritis via induction of TGF-beta and downregulation of proinflammatory mediators, Clin. Exp. Immunol. 129 (2002), pp. 232-239.

H.T. Yu, F. Ye, F.P. Yuan, L. Cai, H.L. Ji and B.B. Keller, Neonatal murine engineered cardiac tissue toxicology model: Impact of metallothionein overexpression on cadmiuminduced injury, Toxicol. Sci. 165 (2018), pp. 499-511.

M. Zalewska, J. Trefon and H. Milnerowicz, The role of metallothionein interactions with other proteins, Proteomics 14 (2014), pp. 1343-1356.

K. Zangger, G. Shen, G. Oz, J.D. Otvos and I.M. Armitage, Oxidative dimerization in metallothionein is a result of intermolecular disulphide bonds between cysteines in the alphadomain, Biochemical J. 359 (2001), pp. 353-360.

S. Zbinden, J. Wang, R. Adenika, M. Schmidt, J.U. Tilan, A.H. Najafi, X. Peng, R.M. Lassance-Soares, M. Iantorno, H. Morsli, L. Gercenshtein, G.J. Jang, S.E. Epstein and M.S. Burnett, Metallothionein enhances angiogenesis and arteriogenesis by modulating smooth muscle cell and macrophage function, Arter. Thromb. Vasc. Biol. 30 (2010), pp. 477-482.

J.D. Zeng, N. Zhang, G.J. Zhao, L.X. Xu, Y. Yang, X.Y. Xu, M.K. Chen, H.Y. Wang, S.X.F. Zheng and X.X. Li, MT1G is silenced by DNA methylation and contributes to the pathogenesis of hepatocellular carcinoma, J. Cancer 9 (2018), pp. 2807-2816.

J. Zhang, R.J. Sun, Y. Liu, G.N. Wang and Q.L. Wang, Metallothionein lower underexpression in benign tumors than that in malignant tumors: Systematic review article and meta-analysis, Iran J. Public Health 43 (2014), pp. 696-704.

S. Zhang, X.B. Liu, T. Bawa-Khalfe, L.S. Lu, Y.L. Lyu, L.F. Liu and E.T.H. Yeh, Identification of the molecular basis of doxorubicin-induced cardiotoxicity, Nat. Med. 18 (2012), pp. 1639-1642.

Y.L. Zheng, L.H. Jiang, Y.X. Hu, C. Xiao, N. Xu, J.Y. Zhou and X.H. Zhou, Metallothionein $1 \mathrm{H}(\mathrm{MT} 1 \mathrm{H})$ functions as a tumor suppressor in hepatocellular carcinoma through regulating Wnt/beta-catenin signaling pathway, BMC Cancer 17 (2017), pp. 1-11.

B. Zhitomirsky and Y.G. Assaraf, Lysosomes as mediators of drug resistance in cancer, Drug Resist. Updat. 24 (2016), pp. 23-33.

O. Zitka, J. Kukacka, S. Krizkova, D. Huska, V. Adam, M. Masarik, R. Prusa and R. Kizek, Matrix metalloproteinases, Curr. Med. Chem. 17 (2010), pp. 3751-3768. 